\title{
Advances in Designing Au Nanoparticles for Catalytic Epoxidation of Propylene with $\mathrm{H}_{2}$ and $\mathrm{O}_{2}$
}

\author{
Van-Huy Nguyen ${ }^{1,2, * \mathbb{C}}$, Ba-Son Nguyen ${ }^{3, *} \mathbb{\infty}$, Chechia Hu ${ }^{4} \mathbb{1}$, Ajit Sharma ${ }^{5}$, Dai-Viet N. Vo ${ }^{6} \mathbb{C}$,

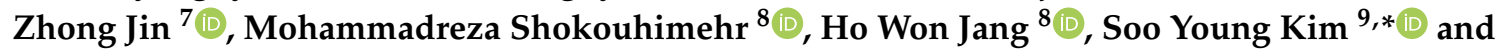 \\ Quyet Van Le ${ }^{10, *(1)}$ \\ 1 Department for Management of Science and Technology Development, Ton Duc Thang University, \\ Ho Chi Minh City 700000, Vietnam \\ 2 Faculty of Applied Sciences, Ton Duc Thang University, Ho Chi Minh City 700000, Vietnam \\ 3 Key Laboratory of Advanced Materials for Energy and Environmental Applications, Lac Hong University, \\ Bien Hoa 810000, Vietnam \\ 4 Department of Chemical Engineering, R\&D Center for Membrane Technology and Research Center for \\ Circular Economy, Chung Yuan Christian University, Chungli Dist., Taoyuan City 32023, Taiwan; \\ chechiahu@cycu.edu.tw \\ 5 School of Chemical Engineering and Physical Science, Lovely Professional University, Jalandhar 144411, \\ India; ajitsharma2003@gmail.com \\ 6 Center of Excellence for Green Energy and Environmental Nanomaterials (CE@GrEEN), Nguyen Tat Thanh \\ University, 300A Nguyen Tat Thanh, District 4, Ho Chi Minh City 755414, Vietnam; daivietvnn@yahoo.com \\ 7 Jiangsu Key Laboratory of Advanced Organic Materials, Key Laboratory of Mesoscopic Chemistry of MOE, \\ School of Chemistry and Chemical Engineering, Nanjing University, Nanjing 210023, Jiangsu, China; \\ zhongjin@nju.edu.cn \\ 8 Department of Materials Science and Engineering, Research Institute of Advanced Materials, Seoul National \\ University, Seoul 08826, Korea; mrsh2@snu.ac.kr (M.S.); hwjang@snu.ac.kr (H.W.J.) \\ 9 Department of Materials Science and Engineering, Korea University, 145, Anam-ro Seongbuk-gu, \\ Seoul 02841, Korea \\ 10 Institute of Research and Development, Duy Tan University, Da Nang 550000, Vietnam \\ * Correspondence: nguyenvanhuy@tdtu.edu.vn (V.-H.N.); nbsonhd@gmail.com (B.-S.N.); \\ sooyoungkim@korea.ac.kr (S.Y.K.); levanquyet@dtu.edu.vn (Q.V.L.)
}

Received: 29 March 2020; Accepted: 17 April 2020; Published: 20 April 2020

check for updates

\begin{abstract}
Au nanoparticles, which can be used in various industrial and environmental applications, have drawn substantial research interest. In this review, a comprehensive background and some insights are provided regarding recent studies concerning the use of Au nanoparticles for catalytic propylene epoxidation with $\mathrm{H}_{2}$ and $\mathrm{O}_{2}$. Over the last two decades, substantial progress has been made toward the efficient production of propylene oxide (PO); this includes the design of highly dispersed Au catalysts on Ti-modified mesoporous silica supports, the optimization of catalytic epoxidation, and the determination of the mechanisms and reaction pathways of epoxidation. Particularly, the critical roles of catalyst synthesis, the types of material support, Au nanoparticle sizes, and the dispersion amounts of $\mathrm{Au}$ nanoparticles are emphasized in this review. In future studies, novel, practical, robust, and highly PO-selective Au nanoparticle catalyst systems are expected to be continually designed for the enhanced catalytic epoxidation of propylene.
\end{abstract}

Keywords: Au nanoparticles; catalysts; propylene epoxidation; nanomaterials

\section{Introduction}

Propylene oxide (PO), which is the second most crucial chemical building block after ethylene oxide, is extensively used for the fabrication of several valuable products $[1,2]$. To date, several 
processes, such as the chlorohydrin, hydroperoxide (indirect oxidation or coproducts), hydrogen peroxide, direction oxidation, electrochemical, and biochemical processes, have been proposed to produce $\mathrm{PO}$, as summarized in Figure 1 [3-5].

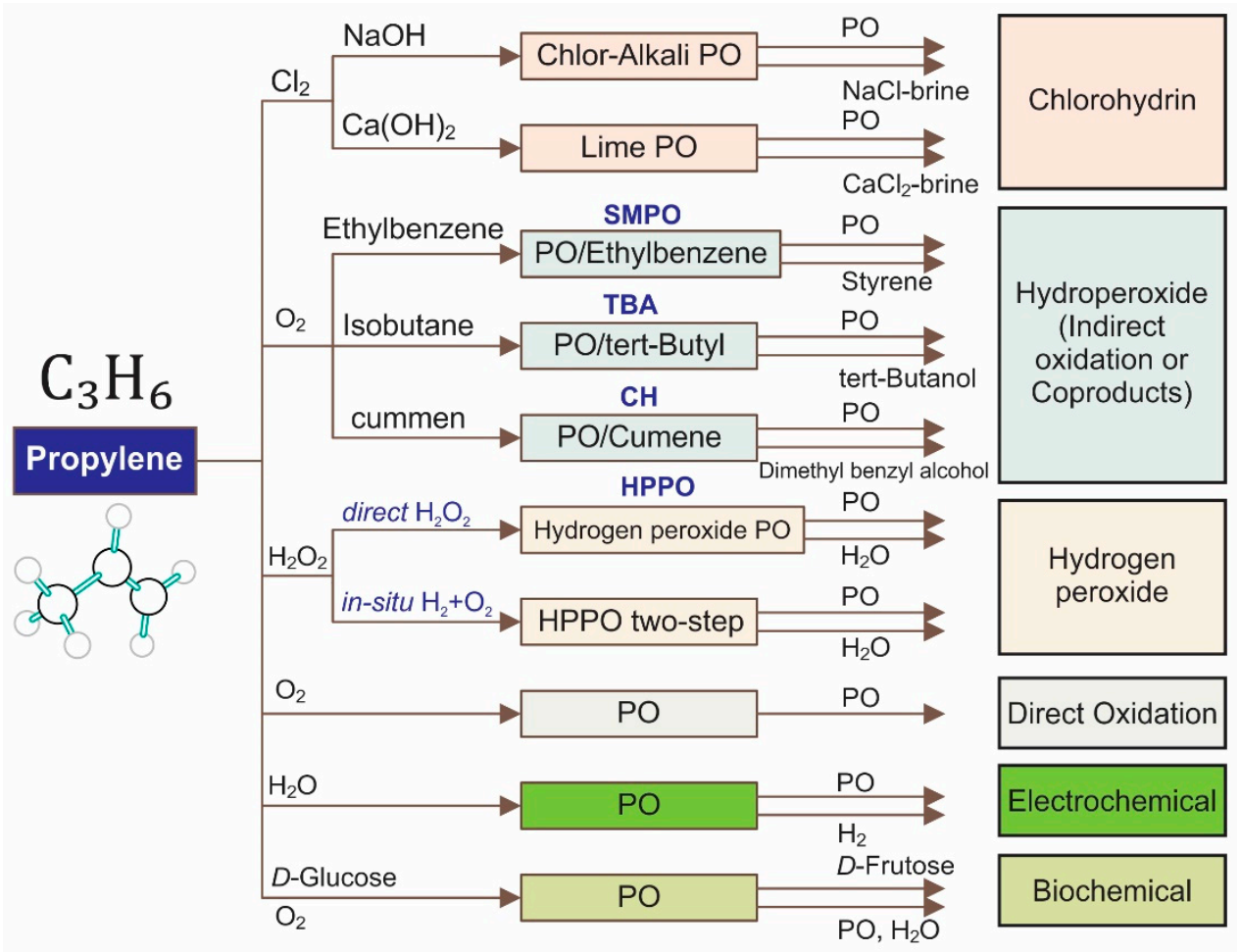

Figure 1. Various processes for producing propylene oxide.

Although the chlorohydrin processes play the most significant role in epoxide propylene in the industry currently, these processes involve the dehydrochlorination of chlorohydrins, leading to the formation of various harmful byproducts (brine of chlorine salts). Hydroperoxide (indirect oxidation or coproducts) processes-including styrene monomer propylene oxide (SMPO), ter-butyl alcohol (TBA), and cumene hydroperoxide $(\mathrm{CH})$-are more friendly to the environment. However, these routes produce a significant amount of coproducts (styrene, ter-butyl alcohol, and dimethyl benzyl alcohol), which heavily depend on market demand. Other processes, such as direction oxidation (catalytic epoxidation and photocatalytic epoxidation), electrochemical, and biochemical processes, also receive considerable attention [1,2,6-13]. It is noted that an excellent turnover frequency (TOF, $12 \mathrm{~s}^{-1}$ ) could be observed via the biological process [6]. However, the significant challenges of this process are the product toxicity toward microorganisms and the stability of the enzymes. For the direction oxidation, their current TOF is still far from the requirement for industrial-scale production. Among alternative processes for the epoxidation of propylene, the hydrogen peroxide propylene oxide (HPPO) route has been gaining attention, which offers several advantages compared to the traditional chlorohydrin and coproduct processes. For example, there are no chlorinated compounds involved that could potentially be harmful to the environment, as observed in the chlorohydrin processes, and there is no production of coproducts with lower demand and market values, as observed in the hydroperoxide process. However, the high production cost of hydrogen peroxide makes the processes involving hydrogen peroxide unsustainable. Fortunately, there is a proposed HPPO two-step process that involves the in situ production of hydrogen peroxide via the presence of $\mathrm{O}_{2}$ and $\mathrm{H}_{2}$. Hayashi et al. firstly reported that using a mixture of $\mathrm{O}_{2}$ and $\mathrm{H}_{2}$ with $\mathrm{Au}$ nanoparticles (2-5 nm) dispersed in titanium dioxide $\left(\mathrm{TiO}_{2}\right)$ could effectively epoxidize propylene to yield PO with favorable results (PO selectivity $>90 \%$, propylene conversion $=1 \%-2 \%$ ) [14]. The proposed reaction pathway for the epoxidation of propylene has two steps: (1) hydrogen peroxide is firstly produced on the Au surfaces, and then (2) hydrogen 
peroxide is transported close to $(-\mathrm{OOH})$ on the tetrahedral-coordinated $\mathrm{Ti}^{4+}$ centers to react with propylene (Figure 2) [15-17]. Since the proposal of the aforementioned pathway, extensive research has been carried out with regard to designing novel supported Au catalysts (e.g., Au/Ti-contained catalysts) for driven epoxidation.

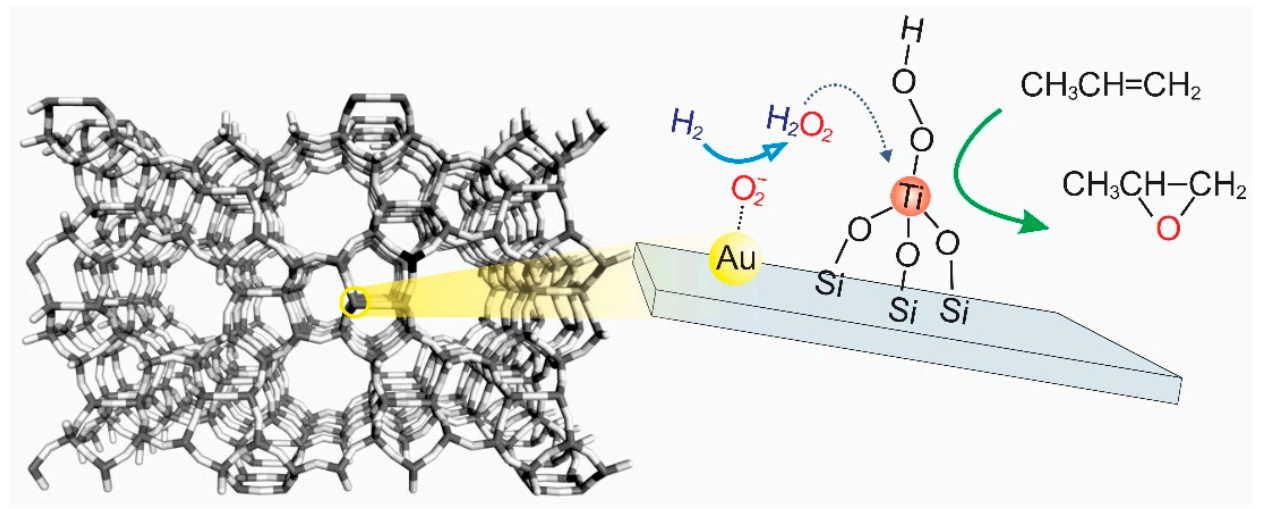

Figure 2. A schematic of Au dispersion on titanosilicate supports and the possible reaction pathways of propylene epoxidation.

Herein, we report a comprehensive background and some insights on the use of Au nanoparticles for catalytic propylene epoxidation with $\mathrm{O}_{2}$ and $\mathrm{H}_{2}$. Special attention is directed toward the fabrication of Au nanoparticles for the catalytic epoxidation of propylene. Furthermore, substantial progress on the matter is reviewed, including the design of highly dispersed Au catalysts on Ti-modified mesoporous silica supports, the optimization of the catalytic epoxidation conditions, and the determination of the mechanisms and reaction pathways of epoxidation.

\section{Relationship between the Structural Catalyst and Catalytic Performance}

\subsection{Size Dependent Reactivity of Au Nanoparticles}

As the pioneers in this field, Haruta et al. firstly proposed that Au nanoparticles $(<5 \mathrm{~nm})$ with various supports, such as $\alpha-\mathrm{Fe}_{2} \mathrm{O}_{3}, \mathrm{Co}_{3} \mathrm{O}_{4}$, and $\mathrm{NiO}$, effectively promote the oxidation of carbon monoxide [18]. This study revealed a new concept for several catalytic applications, including catalytic epoxidation. Haruta et al. also found that Au nanoparticles $(2-5 \mathrm{~nm})$ deposited on anatase $\mathrm{TiO}_{2}$ [14], Ti-MCM-41 [19], and Ti-MCM-48 [15] were crucial for the successful epoxidation of propylene. Hayashi et al. reported that Au hemispherical particles $(<4 \mathrm{~nm})$ enhance epoxidation, with excellent selectivity to PO $(>90 \%)$ and that Au particles with sizes less than $2 \mathrm{~nm}$ promote the production of propane [14]. Feng et al. reported that the influence of average-sized Au particles on catalytic epoxidation (e.g., PO selectivity and PO formation rate) increases as the dispersion amount of $\mathrm{Au}$ nanoparticles increases (0.06-0.40 wt.\%) (Figure 3a-e) [20]. $\mathrm{PO}$ and $\mathrm{H}_{2}$ selectivity and the $\mathrm{PO}$ formation rate increase remarkably as the $\mathrm{Au}$ particle size decreases (Figure 3f,g). Continuing their work on Au supported titanosilicates, Taylor et al. showed that significant activity is attributed to Au nanoparticles $(<2 \mathrm{~nm})$, and $116 \mathrm{~g}_{\mathrm{PO}} \cdot \mathrm{kg}_{\mathrm{cat}}{ }^{-1} \cdot \mathrm{h}^{-1}$ is the highest $\mathrm{PO}$ formation rate that could be observed for $0.05 \mathrm{wt} . \% \mathrm{Au} / \mathrm{TS}-1(\mathrm{Si} / \mathrm{Ti}=36)$ at $200^{\circ} \mathrm{C}$ [21]. Huang et al. clearly indicated that the catalytic activity of Au clusters (1-2 nm) on exterior TS-1 surfaces was higher than that of smaller Au clusters $(<0.55 \mathrm{~nm})$ inside TS-1 micropores [22]. The results are summarized in Table 1. In most of these studies, Au particles with their sizes in the range of $2-5 \mathrm{~nm}$ are considered as the active sites for the epoxidation of propylene $[21,23]$. This suggests that controlling the size of Au nanoparticles strongly influences the catalytic epoxidation performance. 
Table 1. The catalytic epoxidation of propylene with $\mathrm{O}_{2}$ and $\mathrm{H}_{2}$ mixture over Au nanoparticles.

\begin{tabular}{|c|c|c|c|c|c|c|c|}
\hline No. & Type of Catalysts & $\begin{array}{c}\text { Au Particle } \\
\text { Diameter (nm) }\end{array}$ & Reaction Conditions & PO Selectivity (\%) & $\begin{array}{c}\mathrm{C}_{3} \mathrm{H}_{6} \\
\text { Conversion (\%) } \\
\end{array}$ & $\begin{array}{l}\text { PO Formation Rate } \\
\left(\mathrm{g}_{\mathrm{PO}} \cdot \mathrm{kg}_{\mathrm{cat}}{ }^{-1} \cdot \mathrm{h}^{-1}\right)\end{array}$ & Ref./Year \\
\hline 1 & $0.98 w t . \% \mathrm{Au} / \mathrm{TiO}_{2}$ & $2.3 \pm 0.1$ & $\begin{array}{l}\text { Feed gas, } \mathrm{C}_{3} \mathrm{H}_{6} / \mathrm{O}_{2} / \mathrm{H}_{2} / \mathrm{Ar}=10 / 10 / 10 / 70 ; \text { flow } \\
\text { rate, } 2000 \mathrm{~mL} \cdot \mathrm{h}^{-1} ; \text { catalyst, } 0.5 \mathrm{~g} ; \mathrm{T}=323 \mathrm{~K}\end{array}$ & $>99$ & 1.1 & 11.6 & \multirow[t]{2}{*}[14]{$/ 1998$} \\
\hline 2 & 3.2wt. $\% \mathrm{Au} / \mathrm{TiO}_{2}$ & N/A & $\begin{array}{l}\text { Feed gas, } \mathrm{C}_{3} \mathrm{H}_{6} / \mathrm{O}_{2} / \mathrm{H}_{2} / \mathrm{Ar}=10 / 10 / 10 / 70 ; \text { flow } \\
\text { rate, } 2000 \mathrm{~mL} \cdot \mathrm{h}^{-1} ; \text { catalyst, } 0.1 \mathrm{~g} ; \mathrm{T}=323 \mathrm{~K}\end{array}$ & 96 & 0.6 & 31.4 & \\
\hline 3 & $\begin{array}{c}\text { 1wt.\%Au/ Ti-MCM-41 } \\
\text { (C16TMACl, Si/Ti = 100/3) }\end{array}$ & $2.0 \pm 0.4$ & 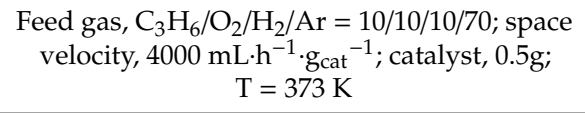 & 92 & 2.84 & N/A & {$[19] / 2001$} \\
\hline 4 & $\begin{array}{l}0.3 w t . \% \mathrm{Au} / \mathrm{Ti}-\mathrm{MCM}-48 \\
\quad(\mathrm{Si} / \mathrm{Ti}=50)\end{array}$ & 2.0 & $\begin{array}{c}\text { Feed gas, } \mathrm{C}_{3} \mathrm{H}_{6} / \mathrm{O}_{2} / \mathrm{H}_{2} / \mathrm{Ar}=10 / 10 / 10 / 70 ; \text { space } \\
\text { velocity, } 4000 \mathrm{~mL} \cdot{ }^{-1} \cdot \mathrm{gcat}^{-1} ; \text { catalyst, } 0.5 \mathrm{~g} \\
\mathrm{~T}=423 \mathrm{~K}\end{array}$ & 92 & 4.5 & N/A & {$[15] / 2002$} \\
\hline 5 & $0.06 \mathrm{wt} . \% \mathrm{Au} / \mathrm{TS}-1$ & 2.6 & \multirow{2}{*}{$\begin{array}{l}\text { Feed gas, } \mathrm{C}_{3} \mathrm{H}_{6} / \mathrm{O}_{2} / \mathrm{H}_{2} / \mathrm{Ar}=10 / 10 / 10 / 70 ; \text { space } \\
\text { velocity, } 14000 \mathrm{~mL}^{-1} \cdot \mathrm{g}_{\text {cat }}{ }^{-1} ; \text { catalyst, } 0.15 \mathrm{~g} ; \\
\mathrm{T}=473 \mathrm{~K}\end{array}$} & 89.6 & N/A & $0.1464 \mathrm{~mol}_{\mathrm{PO}} \cdot \mathrm{s}^{-1} \cdot \mathrm{mol}_{\mathrm{Au}}{ }^{-1}$ & \multirow{2}{*}[20]{$/ 2014$} \\
\hline 6 & $0.40 \mathrm{wt} . \% \mathrm{Au} / \mathrm{TS}-1$ & 5.1 & & 65 & N/A & $0.0222 \mathrm{~mol}_{\mathrm{PO}} \cdot \mathrm{s}^{-1} \cdot \mathrm{mol}_{\mathrm{Au}}{ }^{-1}$ & \\
\hline 7 & $\begin{array}{l}0.05 \mathrm{wt} . \% \mathrm{Au} / \mathrm{TS}-1 \\
\quad(\mathrm{Si} / \mathrm{Ti}=36)\end{array}$ & $<2$ & $\begin{array}{l}\text { Feed gas, } \mathrm{C}_{3} \mathrm{H}_{6} / \mathrm{O}_{2} / \mathrm{H}_{2} / \mathrm{Ar}=10 / 10 / 10 / 70 ; \text { space } \\
\text { velocity, } 7000 \mathrm{~mL}^{-1} \cdot \mathrm{g}_{\text {cat }}^{-1} \text {; catalyst, } 0.305 \mathrm{~g} \\
\qquad \mathrm{~T}=473 \mathrm{~K}\end{array}$ & 81 & 8.8 & $116 \mathrm{~g}_{\mathrm{PO}} \cdot \mathrm{h}^{-1} \cdot \mathrm{g}_{\mathrm{Au}}{ }^{-1}$ & \multirow{2}{*}[21]{$/ 2005$} \\
\hline 8 & $\begin{array}{l}0.01 \mathrm{wt} . \% \mathrm{Au} / \mathrm{TS}-1 \\
\quad(\mathrm{Si} / \mathrm{Ti}=500)\end{array}$ & $<2$ & $\begin{array}{l}\text { Feed gas, } \mathrm{C}_{3} \mathrm{H}_{6} / \mathrm{O}_{2} / \mathrm{H}_{2} / \mathrm{Ar}=10 / 10 / 10 / 70 ; \text { space } \\
\text { velocity, } 7000 \mathrm{~mL} \cdot \mathrm{h}^{-1} \cdot \mathrm{g}_{\mathrm{cat}}{ }^{-1} ; \text { catalyst, } 0.3185 \mathrm{~g} ; \\
\qquad \mathrm{T}=473 \mathrm{~K}\end{array}$ & 65 & 4 & $350 \mathrm{~g}_{\mathrm{PO}} \cdot \mathrm{h}^{-1} \cdot \mathrm{g}_{\mathrm{Au}}{ }^{-1}$ & \\
\hline 9 & $0.10 \mathrm{wt} . \% \mathrm{Au} / \mathrm{TS}-1$ (SG) & 4.0 & \multirow{2}{*}{$\begin{array}{c}\text { Feed gas, } \mathrm{C}_{3} \mathrm{H}_{6} / \mathrm{O}_{2} / \mathrm{H}_{2} / \mathrm{Ar}=10 / 10 / 10 / 70 ; \text { space } \\
\text { velocity, } 8000 \mathrm{~mL} \cdot \mathrm{h}^{-1} \cdot \mathrm{gcat}^{-1} ; \text { catalyst, } 0.15 \mathrm{~g} ; \\
\mathrm{T}=473 \mathrm{~K}\end{array}$} & 90 & 0.9 & 16 & \multirow{2}{*}[22]{$/ 2011$} \\
\hline 10 & $\begin{array}{l}\text { 0.20wt.\%Au/ } \\
\text { TS-1-Na1(SG) }\end{array}$ & 1.8 & & 84 & 8.3 & 127 & \\
\hline
\end{tabular}



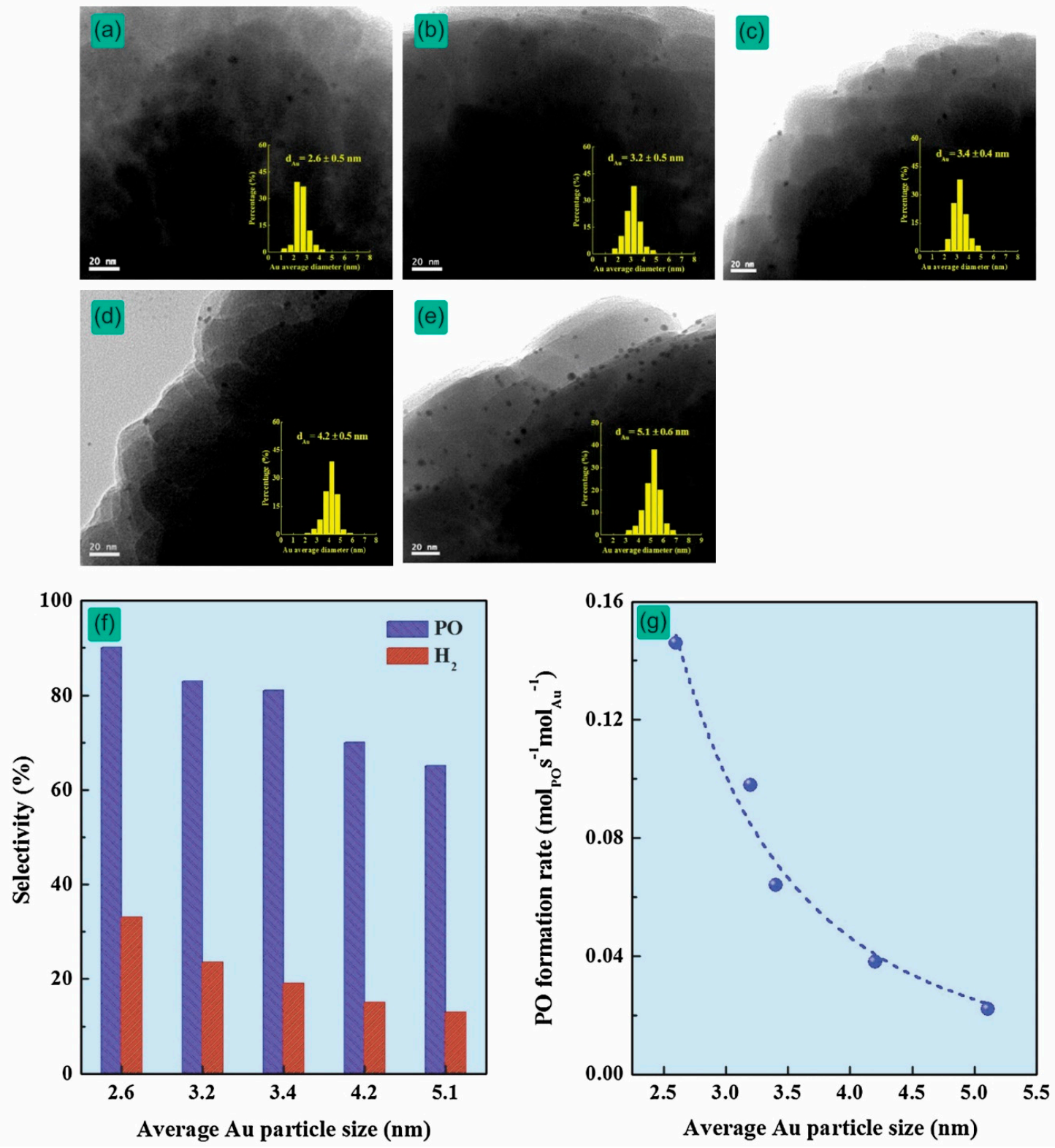

Figure 3. TEM images with the corresponding Au nanoparticle size distributions of the Au/TS-1 catalysts with different Au-loadings: (a) 0.06, (b) 0.12, (c) 0.20, (d) 0.24, and (e) $0.40 \mathrm{wt}$.\%. The correlation between Au nanoparticle sizes and (f) selectivity to propylene oxide (PO) and $\mathrm{H}_{2}$. (g) The PO formation rate over Au/TS-1 catalysts. Reproduced with permission from reference [20], copyright 2014, Elsevier B.V.

Since determining the driving factor of the size-dependent catalytic activity could provide guidelines to continuously improve epoxidation performance, various factors such as the corner, edge, perimeter, and surface sites of Au nanoparticles were determined via theoretical calculations that allow the imaging of the active catalyst [20,24,25]. Feng et al. proposed a simple Au truncated cuboctahedron shapes physical model with $\left(\begin{array}{llll}1 & 1 & 1\end{array}\right)$ and $\left(\begin{array}{lll}1 & 0 & 0\end{array}\right)$ top facets (Figure 4a) [20]. The principles of the model are as follows: (a) the metal atoms occupy crystallographic positions, (b) the numbers of atoms of particles are fixed and predetermined, and (c) the crystallites are efficiently shaped to minimize free energy. Feng et al. assumed that only a single type of Au site plays an active role in the catalytic activity. Based on the above assumptions, the Au atom fraction over different types of site was determined, as shown in Figure 4b. Clearly, perimeter and corner sites played a significant role in the low Au nanoparticle size $(<2 \mathrm{~nm})$. Except for the surface site model, other models showed that $\mathrm{Au}$ nanoparticles would be inactive when the Au nanoparticle was larger than $5 \mathrm{~nm}$. Based on this 
hypothesis, the correlation between the $\mathrm{PO}$ formation rate and the Au nanoparticle size for different types of site model was established, as illustrated in Figure 4c. Clearly, the catalytic performance in surface, edge, and perimeter site models did not strongly depend on the Au nanoparticle size. On the other hand, the performance on the corner site not only gave a strong size dependence but also agreed with the experimental results, suggesting that the Au corner site played the leading role in the promotion of catalytic epoxidation. Some possible reasons could be used to explain the enhanced performance by the corner model as follows: oxygen could be more readily adsorbed on the Au corner [26]; effectively using hydrogen peroxide, which was formed on small Au nanoparticles, could provide a shorter pathway to $\mathrm{Ti}^{4+}$ sites for the catalytic epoxidation of propylene.
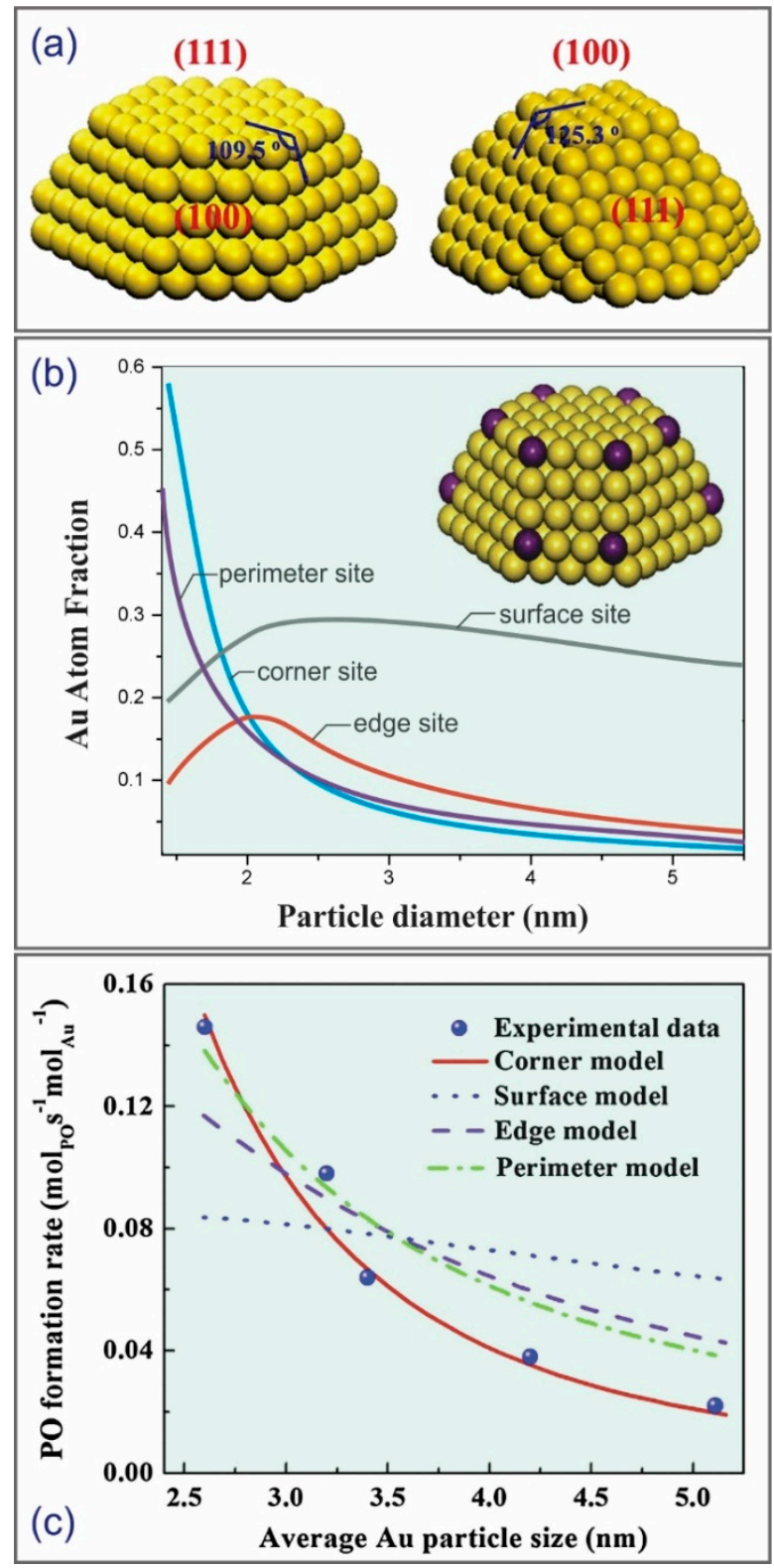

Figure 4. (a) A model of Au truncated cuboctahedron shapes. (b) The fractions of atoms at different sites (surface, corner, edge, and perimeter) and diameters of Au nanoparticles. (c) Calculations based on different sites and experimental data of the PO formation rate over Au/TS-1. Reproduced with permission from reference [20], copyright 2014, Elsevier B.V. 


\subsection{Impact of Support Materials for Au Nanoparticles}

Since the early work by Yap et al. [14], various Au nanoparticle catalysts deposited on different supports were proposed for the epoxidation of propylene [15,19-23,27-47]. There are essentially three functional advantages of support materials for Au nanoparticles. In the first, support materials have a great influence on selective epoxidation products. Haruta et al. reported an important interaction between the Au nanoparticles and the Ti-sites on the support [36]. The anatase structure promoted selectivity to PO, and the $\mathrm{TiO}_{2}$ caused complete combustion to $\mathrm{CO}_{2}$. Additionally, microporous titanium silicates (e.g., TS-1, TS-2, and Ti- $\beta$ zeolite) prefer the formation of propionaldehyde. In the second, support materials play an effective role in enhancing the reactive adsorption ability of reactants and the hydrogen efficiency. Some studies focused on designing isolated and highly dispersed tetrahedral-coordinated Ti-oxide centers in the ligand-to-metal charge-transferred state $\left(\left(\mathrm{Ti}^{4+}-\mathrm{O}^{2-}\right)^{*}\right)$, which is associated with the adsorption of propylene [5,48] and the nucleation sites for Au nanoparticles [49]. In previous studies, $\mathrm{Au}$ nanoparticles were deposited on Ti-modified mesoporous silica supports, such as $\mathrm{SiO}_{2}[27,28]$, TUD [29], SBA-15 [30,31], MCM-41 [19,32,33], MCM-48 [15], MCM-36 [34], YNU-1 [34], MWW [34,35], TS-1 [20-23,37-46,50], and TS-2 [47], to enhance the epoxidation of propylene. In the last, support materials play a key role in slowing the deactivation. Currently, one of the economic and most technical challenges that requires further research is reducing the deactivation of Au-modified catalysts over time. Uphade et al. reported that $\mathrm{Au} / \mathrm{Ti}-\mathrm{MCM}-48$ and $\mathrm{Au} / \mathrm{Ti}-\mathrm{MCM}-41$ exhibit very high initial conversions (5.6\% and $5.1 \%$, respectively); however, these values decrease sharply with time $(2.6 \%-2.7 \%$ after $2 \mathrm{~h}$ of time-on-stream) (Figure 5a) [15]. A similar phenomenon was observed regarding PO selectivity and $\mathrm{H}_{2}$ conversion. The loss of activity is speculated to arise from the aggregation of Au nanoparticles [23]. Other possible reasons include the production of the bidentate species and other organic fragments that block the active sites [43] or micropore blocking in Au-supported microporous catalysts [51]. Recently, $\mathrm{Xu}$ et al. developed novel hybrid core-shell materials that comprise TS-1 zeolite in the core and mesoporous silica in the shell (Figure $5 b$ ). Au nanoparticles were successfully incorporated in the inner mesochannels with the range of $2-4 \mathrm{~nm}$ (Figure 5c) [45]. Interestingly, Au/TS-1@meso-SiO 2 exhibited a stable propylene conversion (2.6\%-2.9\%) and high PO selectivity ( $93 \%-95 \%)$ after $54 \mathrm{~h}$ of time-on-stream (Figure 5d). As observed via the TEM (Figure 5c), the aggregation of Au nanoparticles could be restrained by the confinement of the mesopores during the catalytic reaction, thereby prolonging the stable performance. The detailed two-step reaction is described in Figure 5e: (a) hydrogen peroxide was produced in situ from $\mathrm{H}_{2}$ and $\mathrm{O}_{2}$ via the Au nanoparticles in the shell and (b) hydrogen peroxide was diffused into the Ti-tetrahedral sites located in the micropores of the TS- 1 core to create the Ti-peroxo active species (Ti-OOH) that could epoxidize the $\mathrm{C}=\mathrm{C}$ bond of propylene to generate $\mathrm{PO}$. Feng et al. also proposed that Au dispersed in core-shell TS-1/silicalite- 1 catalysts exhibited high catalytic stability and that the PO formation rate could reach up to $126 \mathrm{~g} \cdot \mathrm{kgcat}^{-1} \cdot \mathrm{h}^{-1}$, with high PO selectivity $(>80 \%$ ), for over $100 \mathrm{~h}$ of time-on-stream (Figure $5 \mathrm{f}, \mathrm{g}$ ) [52]. In another approach, Feng et al. designed a novel hydrophobic hierarchical TS-1 support (HTS-1) that maintained a high PO formation rate $\left(150 \mathrm{~g} \cdot \mathrm{kgcat}^{-1} \cdot \mathrm{h}^{-1}\right)$ for over $100 \mathrm{~h}$ of time-on-stream [53]. The boosting properties of mass transfer and the hydrophobicity of the Au/HTS-1 catalyst diminish coking, extending the high catalytic activity. 

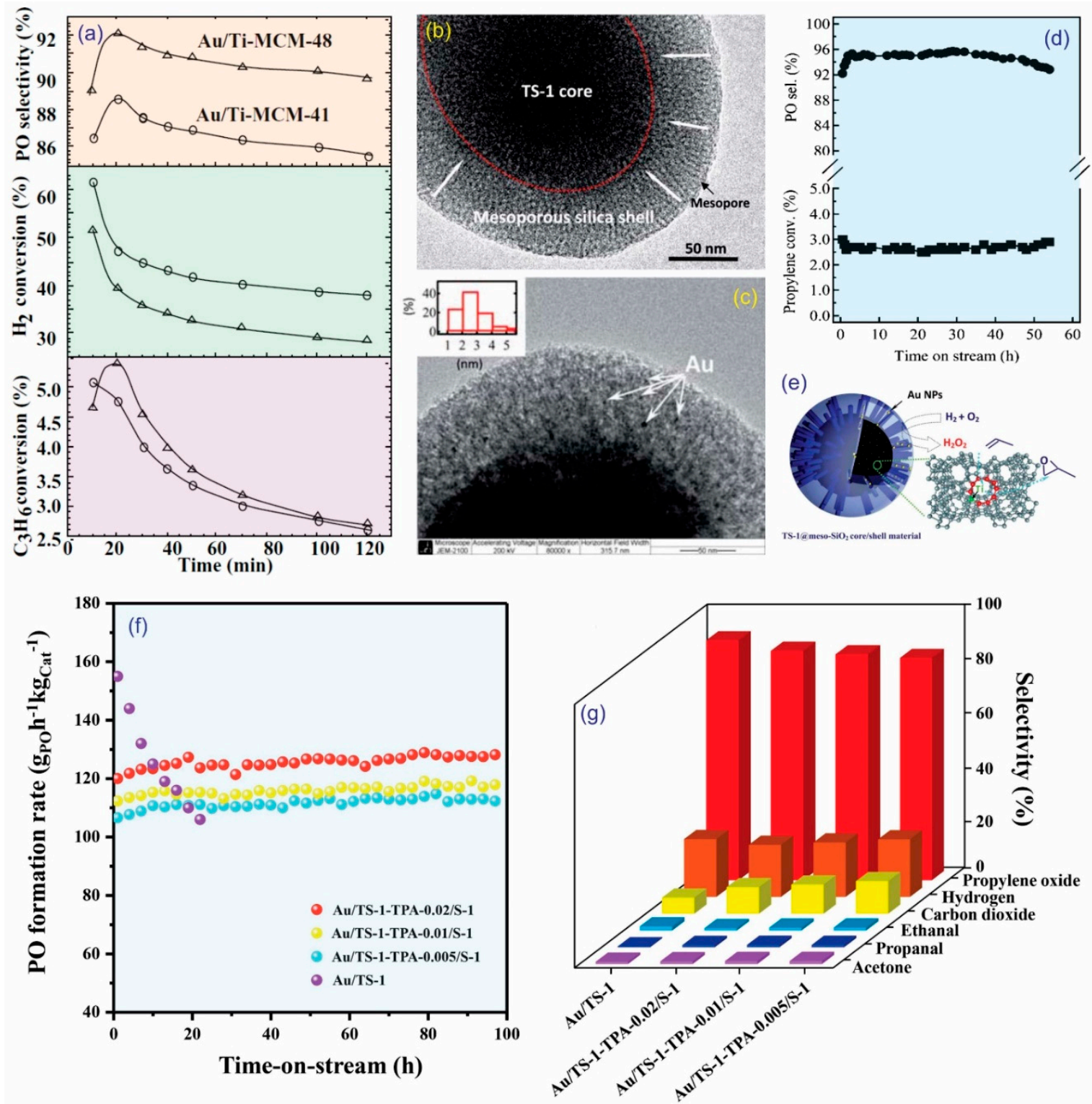

Figure 5. (a) The epoxidation performance of two catalysts: Au/Ti-MCM-41 and Au/Ti-MCM-48. Reproduced with permission from reference [15], copyright 2002, Elsevier B.V. TEM images for (b) TS-1-60@meso-SiO 2 and (c) Au/TS-1-60@meso-SiO . (d) The PO selectivity and propylene conversion of $\mathrm{Au} / \mathrm{TS}-1-60 @$ meso- $\mathrm{SiO}_{2}\left(0.3 \mathrm{~g}\right.$ cat , feed gas $\mathrm{C}_{3} \mathrm{H}_{6} / \mathrm{H}_{2} / \mathrm{O}_{2} / \mathrm{N}_{2}=2 / 2 / 2 / 14 \mathrm{~cm}^{3} \cdot \mathrm{min}^{-1}$, space velocity $=4000 \mathrm{~cm}^{3} \cdot \mathrm{g}_{\mathrm{cat}}{ }^{-1} \cdot \mathrm{h}^{-1}, 423 \mathrm{~K}, 0.1 \mathrm{MPa}$ ). (e) The reaction pathways of epoxidation. (f) The PO formation rate and (g) production distributions of Au/TS-1-based catalysts. Reproduced with permission from references [45,52]. Copyright 2011, Royal Society of Chemistry, and 2019, Elsevier B.V.

\section{Preparation of Dispersed Au Nanoparticle Catalysts}

Taking all of the relationships between the structural catalysts and catalytic performance together, it is scientifically interesting to discuss the preparation methods of dispersed Au nanoparticles. Since the efficiency in the propylene epoxidation strongly depends both on the size of gold nanoparticles and the type of supports, it is clear that the preparation of these catalysts is equally crucial. In most cases, the deposition-precipitation method is used to prepare $\mathrm{Au}-\mathrm{Ti}^{4+}$ catalysts (e.g., $\mathrm{Au} / \mathrm{TS}-1$ ), as $\mathrm{Au}$ nanoparticles can be controlled such that they selectively disperse close to the Ti sites rather than the Si sites [42,54]. On the other hand, the impregnation method has also been proposed; however, this method only produces large spherical Au particles (several tens of nanometers in diameter) that are neither selective nor active for propylene epoxidation [55,56]. Furthermore, solid grinding [22] 
and ionic liquid immobilization [57] methods were also proposed to synthesize $\mathrm{Au}-\mathrm{Ti}^{4+}$ catalysts. The advantages and disadvantages of the proposed methods are as follows.

\subsection{Deposition-Precipitation Method}

Among the several techniques used for dispersing Au nanoparticles on supports, the depositionprecipitation (DP) method has yielded considerably successful results. To examine the effect of DP parameters on Au deposition in TS-1, Yap et al. studied the influence of gold concentrations within the range of $0.98-6.37 \mathrm{wt} . \%$ and a $\mathrm{pH}$ of $4-10$ on the morphology of Au nanoparticles and their catalytic activity [23]. They found that a high $\mathrm{pH}$ promotes gold loading on the support (Figure 6a); however, it does not substantially alter the average size of the Au nanoparticles (Figure 6c,d). The Au capture efficiency is quite low $(<2.5 \%)$ and requires further studies for optimization (Figure $6 \mathrm{~b}$ ).
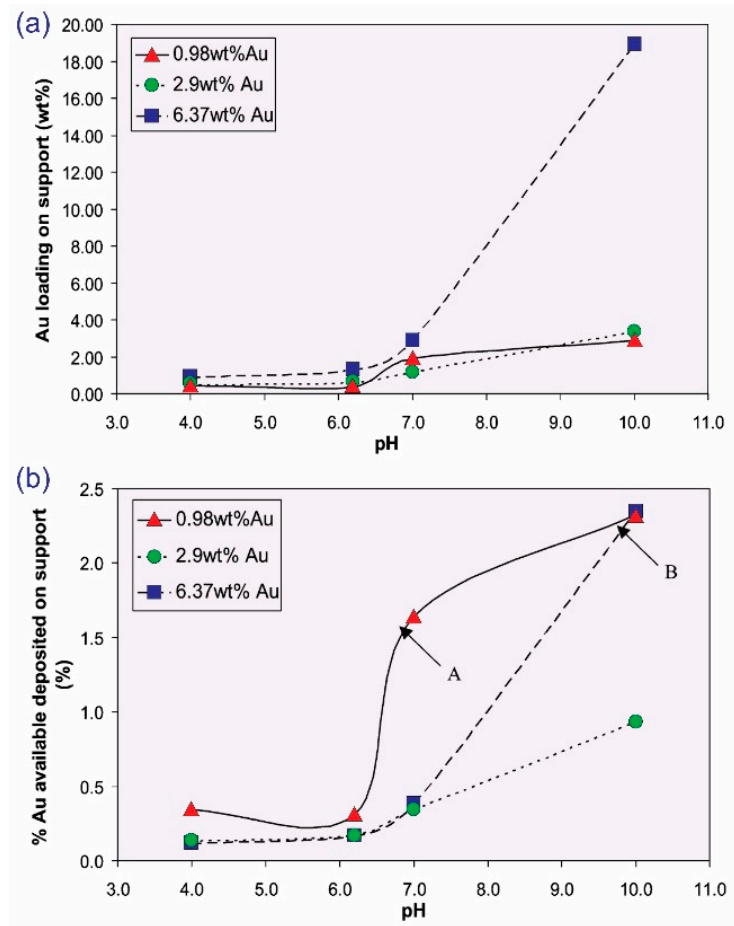

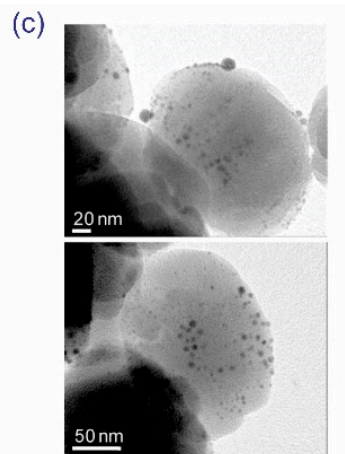

(d)

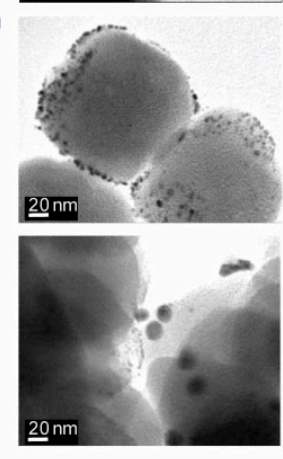

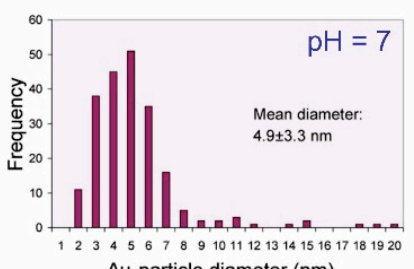

Au particle diameter $(\mathrm{nm})$

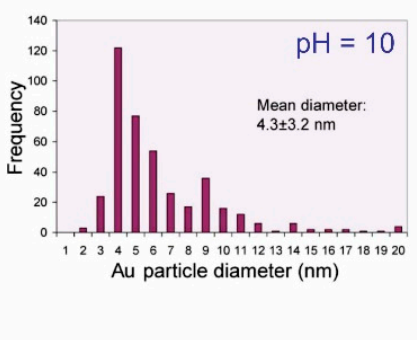

Figure 6. The influence of $\mathrm{pH}$ on (a) Au loading and (b) the percentage of available Au deposited on the support. TEM images and Au particle distributions for the catalysts prepared at (c) $\mathrm{pH} 7$ and (d) $\mathrm{pH}$ 10. Reproduced with permission from reference [23], copyright 2004, Elsevier B.V.

To increase Au capture efficiency, the hydrophobic property of supports should be decreased, the size of the confined Au nanoparticles must be within 2-5nm, and there could be a post-treatment with promoters (e.g., $\mathrm{K}^{+}, \mathrm{Cs}^{+}, \mathrm{Mg}^{2+}, \mathrm{Ca}^{2+}, \mathrm{Sr}^{2+}$, and $\mathrm{Ba}^{2+}$ ) [43], $\mathrm{Cs}^{+}$[33,37], $\mathrm{NH}^{4+}$ [58], trimethylamine [59], and $\mathrm{Ba}^{2+}$ [29]. Lu et al. reported that treatment with $\mathrm{K}^{+}$and $\mathrm{Cs}^{+}$did not affect gold loading, whereas treatment with $\mathrm{Mg}^{2+}, \mathrm{Ca}^{2+}, \mathrm{Sr}^{2+}$, and $\mathrm{Ba}^{2+}$ increased gold loading. The probable mechanisms for this phenomenon are shown in Figure 7 [43]. As TS-1 has a negatively charged surface, it cannot easily attract $\mathrm{Au}$ anions, as shown in Figure $7 \mathrm{a}$. Furthermore, $\mathrm{M}^{+}$might not have a sufficiently strong positive charge; consequently, the $\mathrm{Au}$ anions are not attracted to the support surface (Figure $\mathrm{7b}$ ). By contrast, $\mathrm{M}^{2+}$ possesses a sufficient positive charge to attract $\mathrm{Au}$ anions (Figure 7c). 
(a)
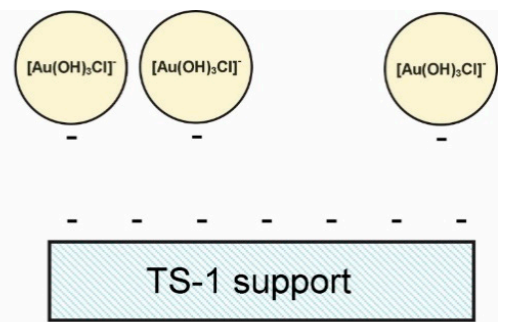

(b)
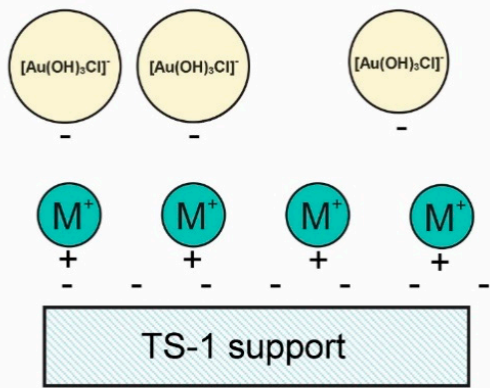

(c)

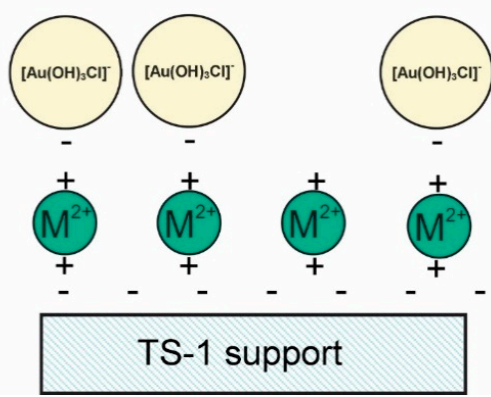

Figure 7. Possible mechanisms for enhancing the attraction of Au anions on the supports via promoters: (a) Au/TS-1, (b) M+-promoted Au/TS-1, and (c) $\mathrm{M}^{2+}$-promoted Au/TS-1 catalysts. Reproduced with permission from reference [43], copyright 2009, Elsevier B.V.

Cumaranatunge and Delgass used $\mathrm{NH}_{4} \mathrm{NO}_{3}$ to post-treat TS-1 supports to enhance the Au capture efficiency [58]. The Au capture efficiency reached up to $69.7 \%$, corresponding to a favorable PO formation rate of $60 \mathrm{~g} \cdot \mathrm{kgcat}^{-1} \cdot \mathrm{h}^{-1}$. In another approach, Feng et al. clearly observed the influence of the slurry aging time in the DP method on the size of the Au nanoparticles [42]. Typically, there is a substantial amount of small-sized Au complexes with a low mass transfer resistance that could migrate into the micropores of the support when the aging time is prolonged. Therefore, the prepared catalyst had a substantial number of small Au nanoparticles inside the micropores, leading to an enhanced PO formation rate (from $4-10 \mathrm{~h}$ of aging, Figure $8 \mathrm{a}$ ). However, further increasing the slurry aging time leads to the dispersion of $\mathrm{Au}(3.2-3.8 \mathrm{~nm}$ in particle size) outside TS-1 (Figure 8b-e), resulting in a decrease in the PO formation rate (18-24 h of aging, Figure 8a).

Notably, Feng et al. found that different charging sequences could influence the transferability of $\mathrm{Au}$ complexes into the micropores of supports. Typically, the post-treatment of prefilling the micropores with $\mathrm{H}_{2} \mathrm{O}$ had the effect of directing Au onto a specific area of the supports, thereby altering the catalytic performance [51]. Feng et al. compared the catalysts that underwent post-treatment via the prefilling of micropores with $\mathrm{H}_{2} \mathrm{O}(\mathrm{Au} / \mathrm{TS}-1-\mathrm{SA})$, catalysts where $\mathrm{NaOH}$ was added (Au/TS-1-SB), and catalysts with no pretreatment (Au/TS-1-SC), as shown in Figure 9. Their average Au particle sizes were similar; however, the numbers of observable Au nanoparticles on the external surfaces of TS-1 were quantitatively different (Au/TS-1-SA $>$ Au/TS-1-SB > Au/TS-1-SC). This observation indicates that most of the Au clusters on the Au/TS-1-SA catalyst are dispersed on the external surface of the support. Moreover, most of the Au clusters on the Au/TS-1-SC catalyst could have traveled inside the micropores of the support, which cannot be easily observed via TEM (Figure 9). 
(a)
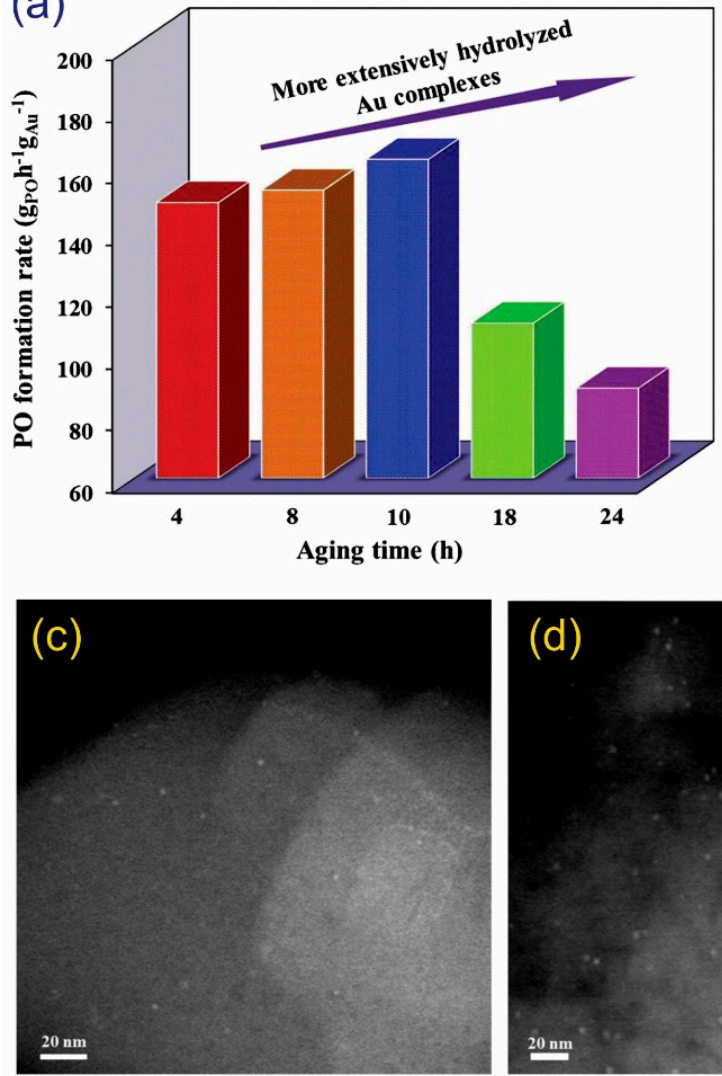

(b)
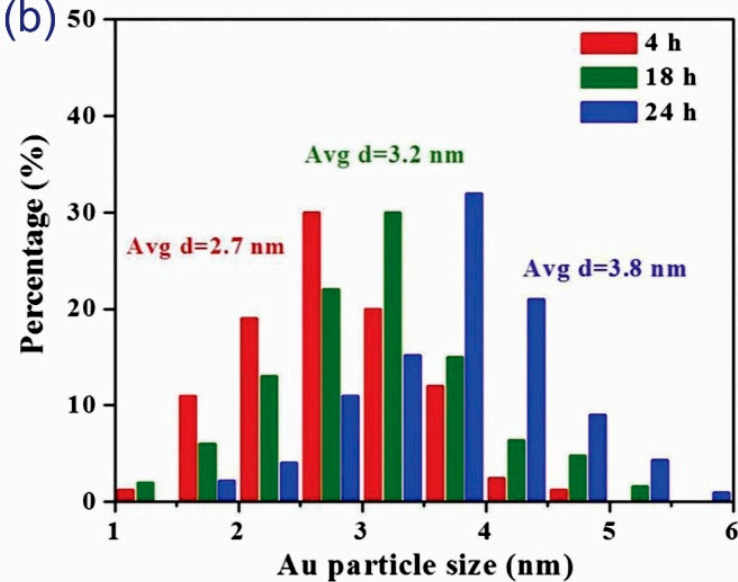

Au particle size (nm)

Figure 8. (a) The influence of aging time on the PO formation rate for Au/TS-1 catalysts. (b) The influence of aging time on the particle size distributions of spent Au/TS-1 catalysts. TEM images of spent Au/TS-1 catalysts under different aging times: (c) 4, (d) 18, and (e) $24 \mathrm{~h}$. Reproduced with permission from reference [42], copyright 2015, Elsevier B.V.

(a)

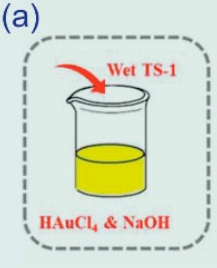

(b)

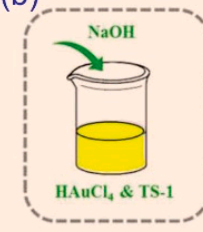

(c)

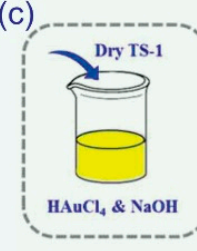

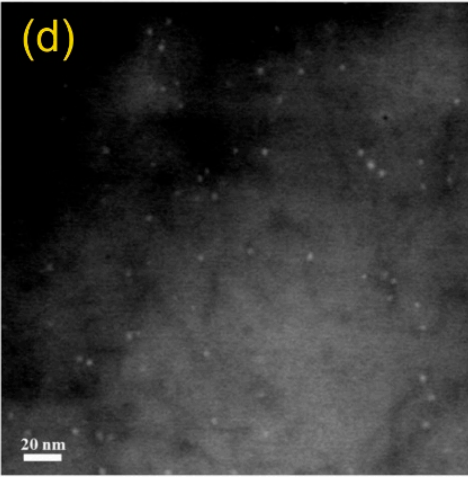

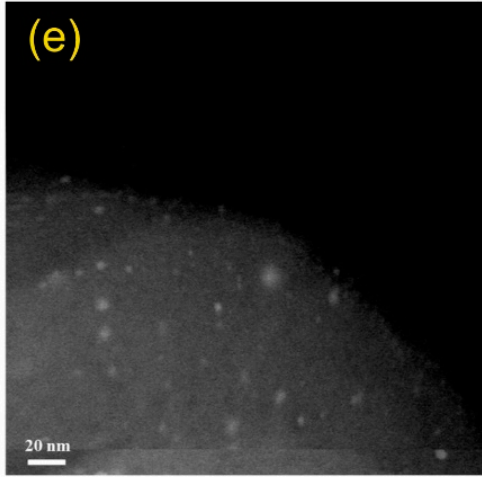

\section{.}




\subsection{Solid Grinding Method}

The solid grinding (SG) method is an effective technique to prepare Au nanoparticles on Ti-modified mesoporous silica supports. Huang et al. proposed a method of depositing small Au nanoparticles $(<2 \mathrm{~nm})$ on TS-1 supports using dimethyl Au (III) acetylacetonate [39]. In this method (Figure 10a), the alkaline pretreatment of the TS- 1 surface creates numerous defects and small mesopores where organic Au complexes could be actively fixed, leading to the formation of confined Au clusters $(<2.0 \mathrm{~nm})$ during the synthesis of the catalyst. Approximately $90 \%$ of the Au nanoparticles had diameters in the range 1.0-2.0 nm (Figure 10c,e). Without pretreatment (Figure 10a), the Au clusters $(<2.0 \mathrm{~nm})$ could easily aggregate to create several large Au nanoparticles (>2.0 nm, Figure 10b,d). Huang et al. suggested that the small Au clusters $(<0.55 \mathrm{~nm})$ deposited on alkaline-treated TS-1 via DP are not active for PO synthesis and that they exhibit a lower PO formation rate than the clusters produced via SG (Au particle sizes in the range 3.2-3.8 nm) [22].
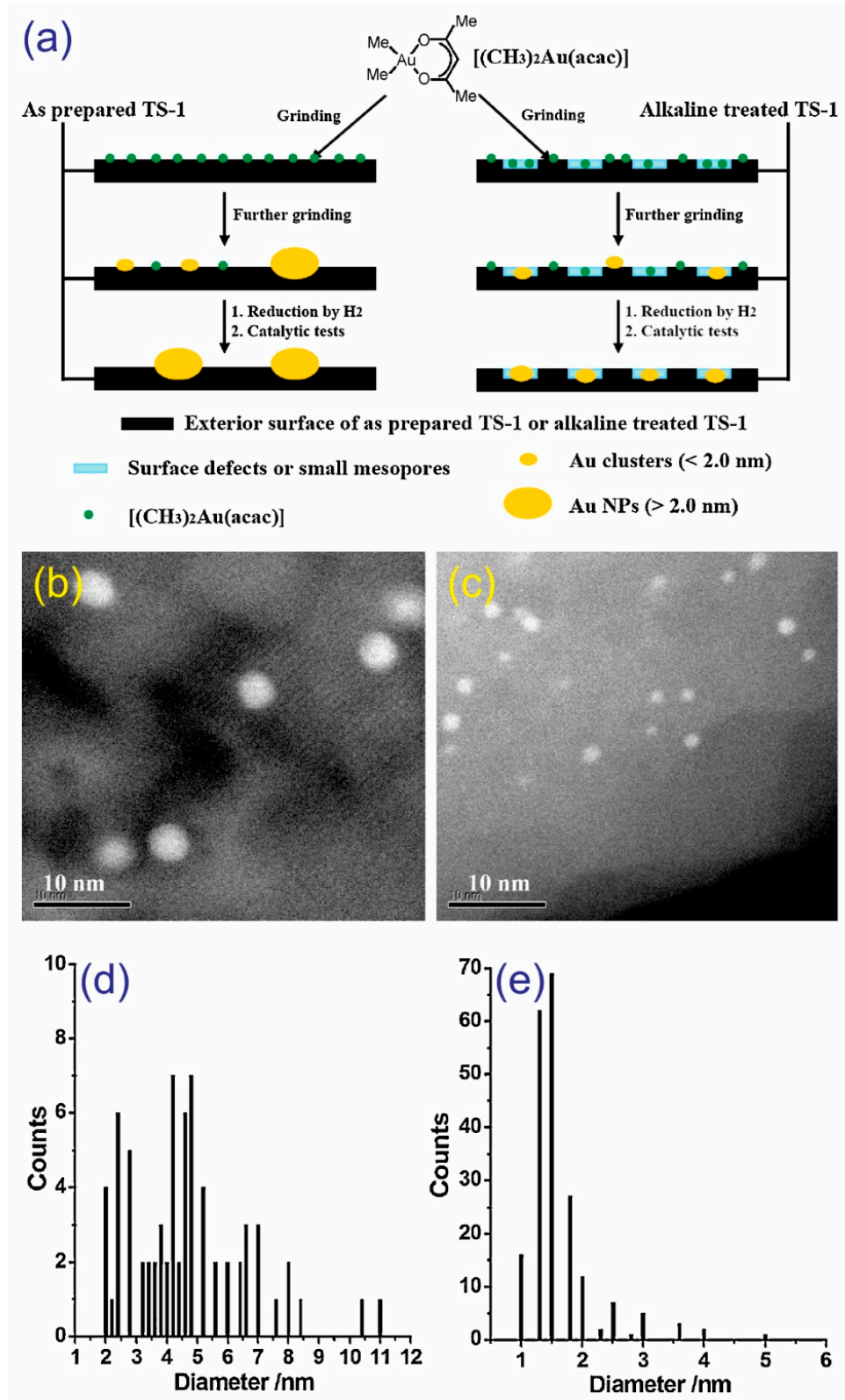

Figure 10. (a) A schematic of the preparation of Au/TS-1 via solid grinding (SG). Corresponding $(\mathbf{b}, \mathbf{c})$ HAADF-STEM images and (d,e) diameter distributions of Au nanoparticles. Reproduced with permission from reference [39], copyright 2010, Elsevier B.V. 


\subsection{Ionic Liquid Immobilization Method}

The ionic liquid immobilization (ILI) technique has been recently proposed to prepare Au nanoparticles catalysts [57]. Here, 1-butyl-3-methylimidazolium tetrafluoroborate was used to alter the surface of TS-1 supports, effectively immobilizing the biosynthesized gold nanoparticles onto the support. Interestingly, ILI could achieve an Au capture efficiency of $100 \mathrm{wt} . \%$, which was higher than that of any other technique. In other studies, Shin et al. successfully used tetrakis(hydroxymethyl)phosphonium chloride/ $\mathrm{NaOH}$ for stabilizing the system [60].

\section{Effect of Reaction Conditions on Catalytic Performance}

The accumulation of knowledge regarding enhanced catalytic epoxidation has led to the addressing of the reaction conditions. Numerous researchers had extensively studied reaction temperature $[21,41,43,57]$, space velocity $[41,61]$, and reactant concentration $[61,62]$.

\subsection{Effect of Reaction Temperature}

Among the reaction parameters for the epoxidation of propylene, reaction temperature plays the most important role, as it correlates to the activation of the reactants and the efficiency of the hydrogen peroxide species in catalytic epoxidation [63]. Du et al. observed that the propylene conversion $(2.7 \%-8.8 \%)$ and PO formation rates $\left(36-115 \mathrm{~g} \cdot \mathrm{kgcat}^{-1} \cdot \mathrm{h}^{-1}\right)$ increase with a rise in the reaction temperature (in the range $220-300^{\circ} \mathrm{C}$ ) (Figure 11a,b) [57]. This result is consistent with the results obtained by Taylor et al. (Figure 11c) [21] and Zhan et al. (Figure 11e) [41]. However, high reaction temperatures do not improve PO selectivity $(81.7 \%-73.8 \%)$ or $\mathrm{H}_{2}$ efficiency $(54.3 \%-21.0 \%)$ (Figure 11a,b,f). As the reaction temperature increases, the selectivity to propanal (Figure 11d) and ethanol (Figure 11f) increases, while the selectivity to PO decreases [21,43].

\subsection{Effect of Space Velocity}

As shown in Figure 12a,b, with the increase in space velocity, the conversion of propylene abruptly decreased, whereas the $\mathrm{PO}$ selectivity and $\mathrm{H}_{2}$ efficiency increased [41]. The loss of catalytic activity might arise from the inadequate contact time of the reactants when the reaction is conducted at high space velocity. To the contrary, low space velocity favors the total oxidation of reactants and products or the further transformation of PO to secondary products, resulting in a decrease in PO selectivity. In another approach, $\mathrm{Lu}$ et al. optimized the reaction process under safe operating conditions. Based on the estimated explosion limits, the simulation was conducted to study the superficial velocity (Figure 12c,d) [61]. To meet the safety requirements, $\Delta \mathrm{UO}_{2}$ must be $\leq 0$. Almost unchanged $\Delta \mathrm{UO}_{2}$ values and hotspot temperatures $(462.8-463.2 \mathrm{~K})$ were obtained, owing to the fact that the feed gas mixture was kept constant, and only a slight change in the wall heat transfer coefficient (hw) was investigated. With the rise in superficial velocity, propylene conversion decreased, while PO selectivity increased. Furthermore, the increase in superficial velocity had a negative effect on the $\mathrm{H}_{2}$ efficiency, PO outlet fraction, and PO yield (Figure 12d).

\subsection{Effect of Reactant Concentration}

From the perspective of chemical safety, attention to the explosion limits of $\mathrm{H}_{2}$ and $\mathrm{O}_{2}$ mixtures is required. Schröder et al. reported that these mixtures could be explosive with $\mathrm{H}_{2}$ concentrations between 3.8 and 95.5 mol.\% [64]. Based on the computational model, Lu et al. studied the influence of the inlet propylene- $\mathrm{H}_{2}$ and $\mathrm{O}_{2}$ partial pressures on the catalytic performance (Figure 13a,b) [61]. To meet the safety requirements, $\Delta \mathrm{UO}_{2}$ must be $\leq 0$; increases in the inlet propylene- $\mathrm{H}_{2}$ and $\mathrm{O}_{2}$ partial pressures increase $\Delta \mathrm{UO}_{2}$, thereby increasing the probability of a severe explosion. Clearly, the increased inlet $\mathrm{H}_{2}$ partial pressure would promote propylene conversion but decrease $\mathrm{PO}$ selectivity and $\mathrm{H}_{2}$ efficiency. By contrast, the inlet propylene partial pressure increases $\mathrm{PO}$ selectivity and $\mathrm{H}_{2}$ efficiency; however, it inhibits propylene conversion (Figure 13a). The higher the inlet $\mathrm{H}_{2}$ and/or propylene 
partial pressure is, the higher the $\mathrm{PO}$ outlet fraction and $\mathrm{PO}$ yield are. The increase in the $\mathrm{O}_{2}$ partial pressure would increase the hotspot temperatures, propylene conversion, $\mathrm{H}_{2}$ efficiency, $\mathrm{PO}$ outlet fraction, and $\mathrm{PO}$ yield (Figure 13b). Based on the experiment, Oyama et al. observed an increase in propylene with an increase in the concentrations of $\mathrm{H}_{2}$ and $\mathrm{O}_{2}$, whereas $\mathrm{PO}$ selectivity and $\mathrm{H}_{2}$ efficiency decreased slightly, resulting in a significant increase in the PO rate (Figure 13c,d) [62]. This system could achieve a propylene conversion of up to $5.9 \%$, PO rate of $90 \mathrm{~g} \cdot \mathrm{kgcat}^{-1} \cdot \mathrm{h}^{-1}$, and $\mathrm{H}_{2}$ efficiency of $9.4 \%$ at the feed composition of $\mathrm{H}_{2} / \mathrm{O}_{2} / \mathrm{C}_{3} \mathrm{H}_{6} / \mathrm{Ar}=40: 40: 10: 10$. Compared to $\mathrm{O}_{2}, \mathrm{H}_{2}$ had a more significant influence on the $\mathrm{PO}$ rate and selectivity.

(a)

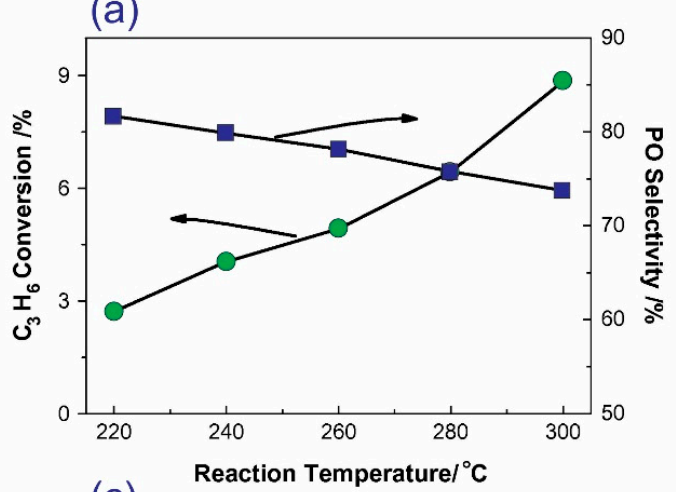

(c)

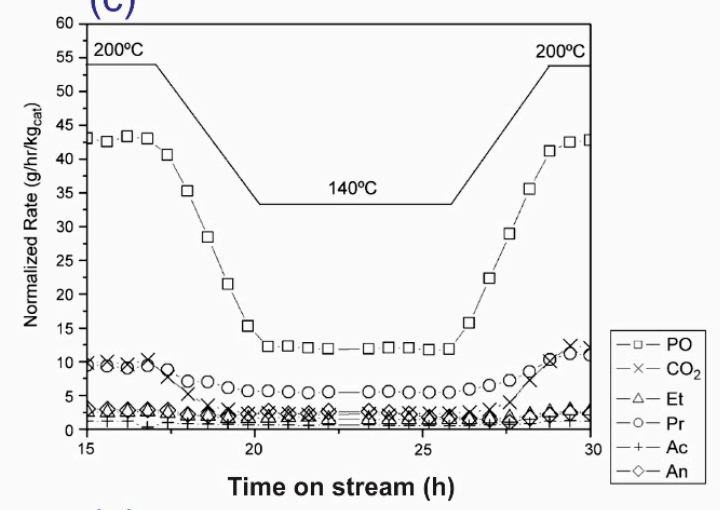

(e)

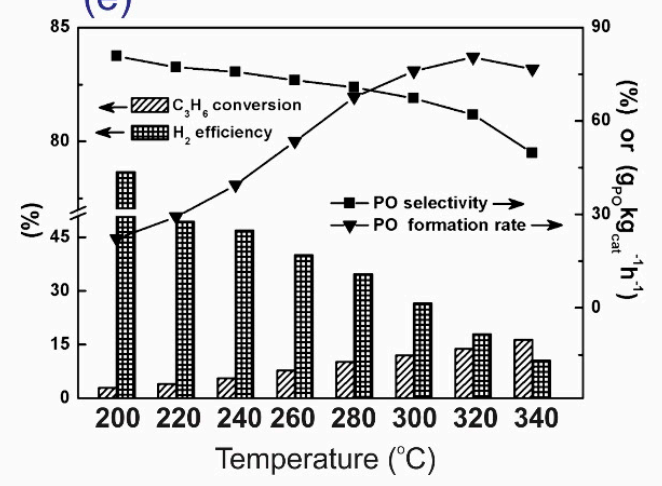

(b)

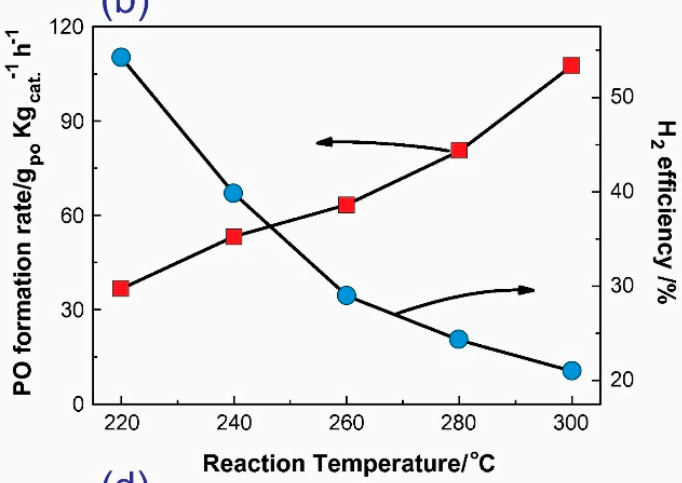

(d) Reaction Temperature $/{ }^{\circ} \mathrm{C}$

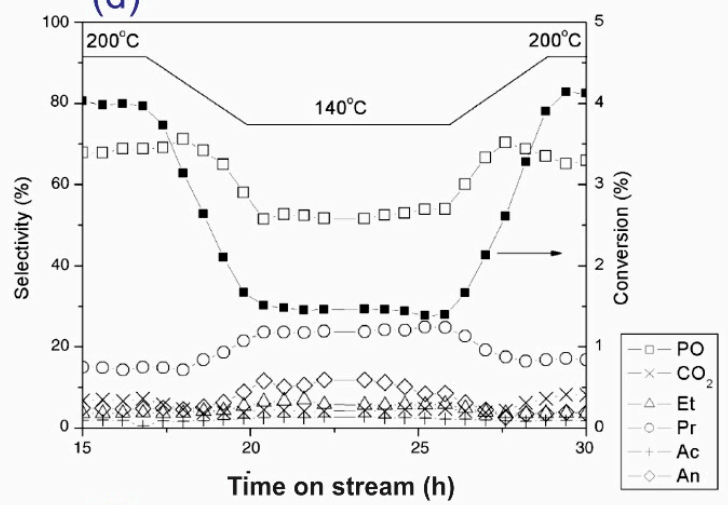

(f)

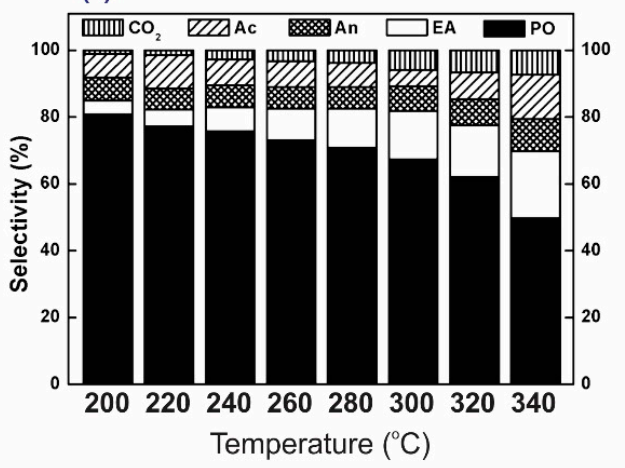

Figure 11. $(\mathbf{a}, \mathbf{b})$ The influence of reaction temperature on the catalytic activity (propylene conversion, $\mathrm{PO}$ selectivity, the $\mathrm{PO}$ formation rate, and the $\mathrm{H}_{2}$ efficiency) of 0.5Au/TS-1(48)-IL. Reproduced with permission from reference [57], copyright 2011, Elsevier B.V. (c,d) The flow of production rates, selectivity, and conversion with time-on-stream in hours over the Au/TS-1(500) catalyst. Reproduced with permission from reference [21]. copyright 2005, Elsevier B.V. (e,f) The influence of reaction temperature on the catalytic activity (propylene conversion, PO selectivity, the PO formation rate, and the $\mathrm{H}_{2}$ efficiency) of Au/TS-1. Reproduced with permission from reference [41], copyright 2011, American Chemical Society. 
(a)

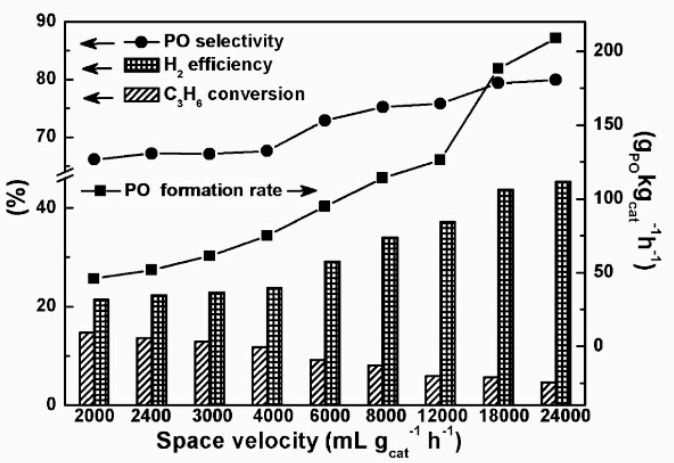

(c)

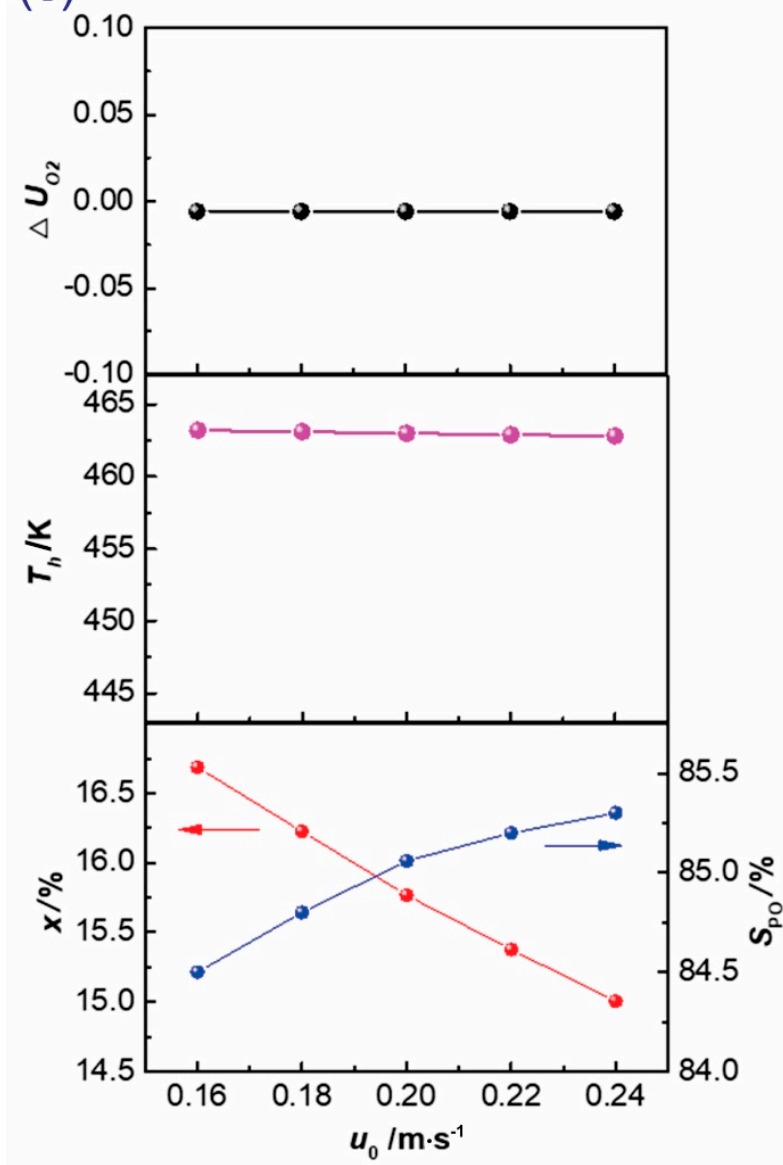

(b)

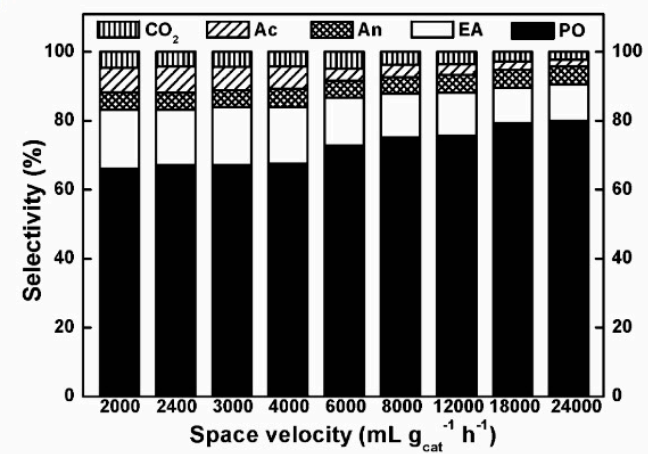

(d)

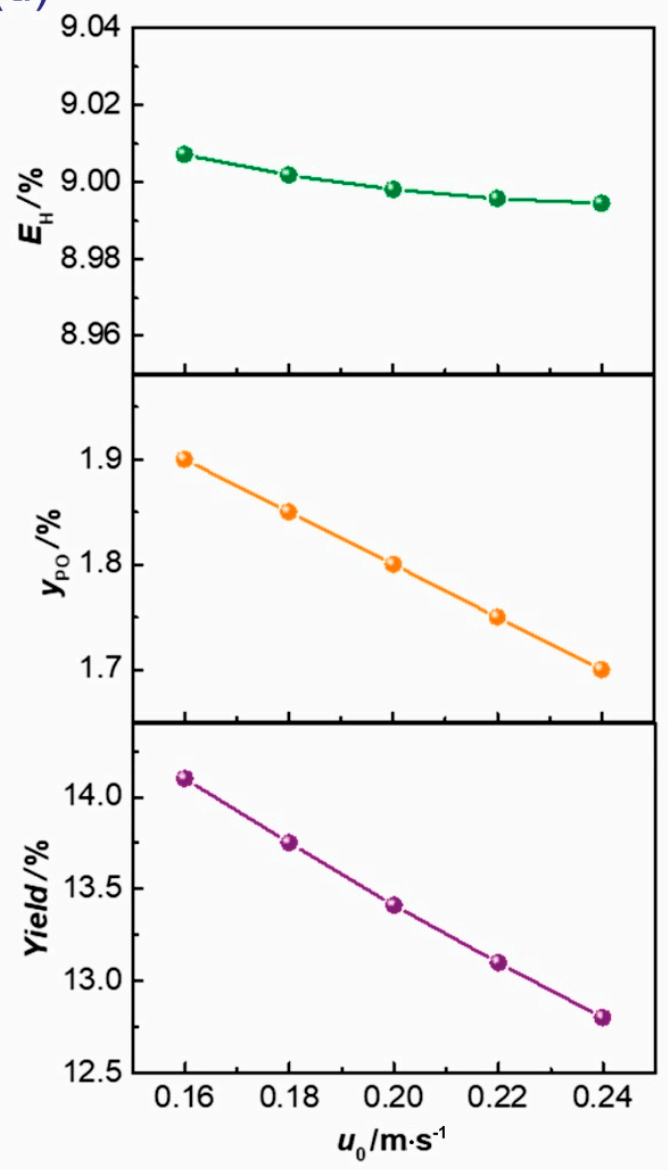

Figure 12. $(\mathbf{a}, \mathbf{b})$ The influence of space velocity on the catalytic activity (propylene conversion, PO selectivity, the $\mathrm{PO}$ formation rate, and the $\mathrm{H}_{2}$ efficiency) of Au/TS-1. Reproduced with permission from reference [41], copyright 2011, American Chemical Society. (c,d) The influence of superficial velocity on the safety requirement, characteristic temperature, and catalytic activity in the computational model. Simulation conditions: $\operatorname{Pin}=100.0 \mathrm{kPa}, \operatorname{Pin}\left(\mathrm{C}_{3} \mathrm{H}_{6}\right)=12.34 \mathrm{kPa}, \operatorname{Pin}\left(\mathrm{H}_{2}\right)=19.23 \mathrm{kPa}, \operatorname{Pin}\left(\mathrm{O}_{2}\right)=12.57 \mathrm{kPa}$, Tin $=443 \mathrm{~K}$. Reproduced with permission from reference [61], copyright 2019, Elsevier B.V. 
(a)
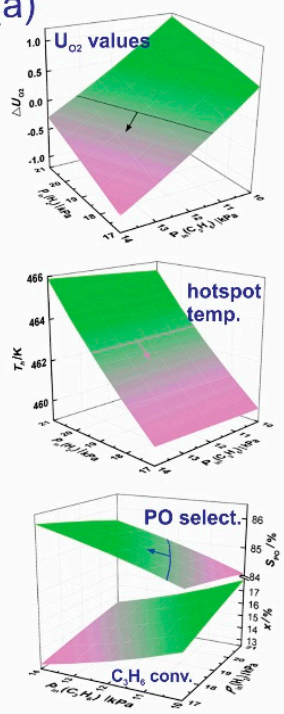
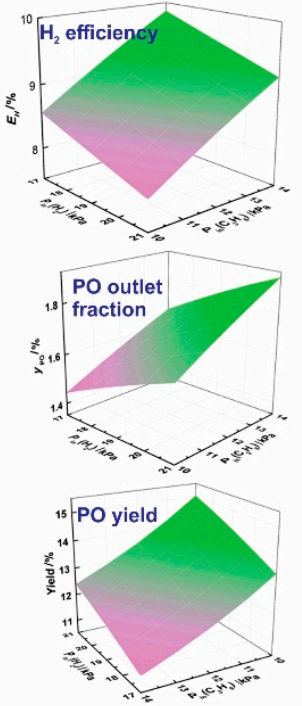

(b)

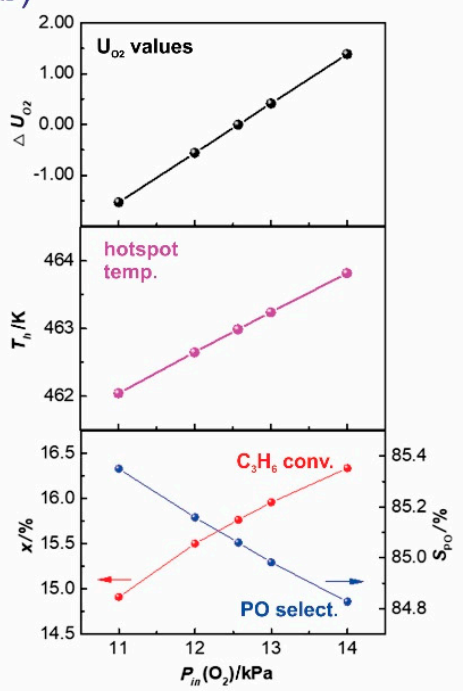

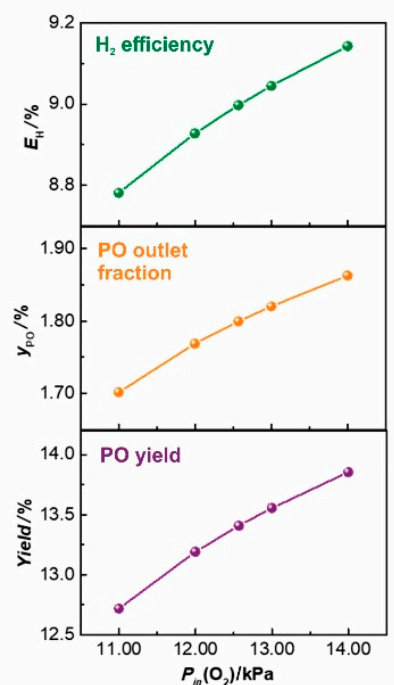

(c)

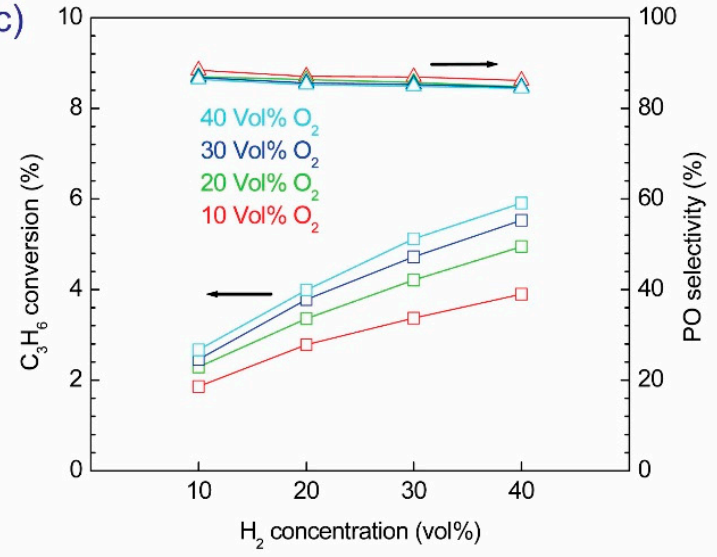

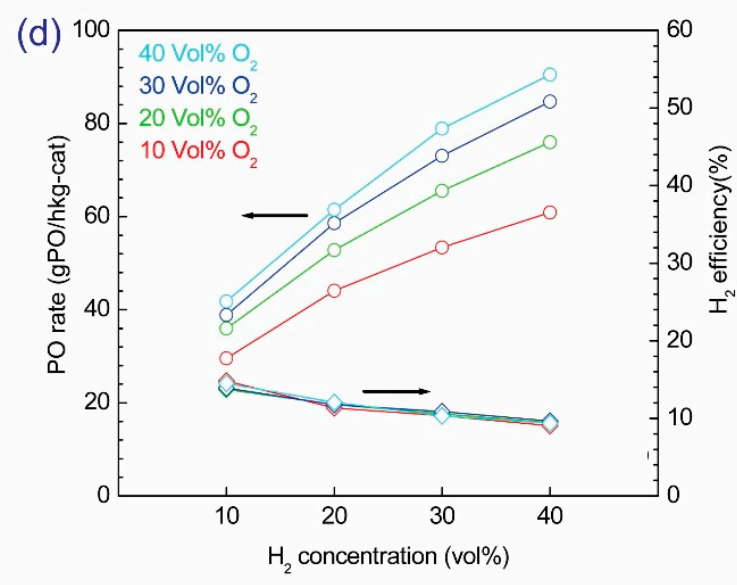

Figure 13. (a) The influence of the inlet propylene and $\mathrm{H}_{2}$ partial pressures on the safety requirements, characteristic temperature, and catalytic activity based on the computational model. Simulation conditions: $\mathrm{u} 0=0.2 \mathrm{~m} \cdot \mathrm{s}^{-1}, \mathrm{Pin}=100.0 \mathrm{kPa}, \operatorname{Pin}(\mathrm{O} 2)=12.57 \mathrm{kPa}$, Tin $=443 \mathrm{~K}$. (b) The influence of inlet $\mathrm{O}_{2}$ partial pressure on the safety requirements, characteristic temperature, and catalytic activity based on the computational model. Simulation conditions: $\mathrm{u} 0=0.2 \mathrm{~m} \cdot \mathrm{s}^{-1}$, $\mathrm{Pin}=100.0 \mathrm{kPa}, \operatorname{Pin}\left(\mathrm{C}_{3} \mathrm{H}_{6}\right)=12.34 \mathrm{kPa}$, $\operatorname{Pin}\left(\mathrm{H}_{2}\right)=19.23 \mathrm{kPa}$, Tin $=443 \mathrm{~K}$. Reproduced with permission from reference [61], copyright 2019, Elsevier B.V. The influence of $\mathrm{H}_{2}$ and $\mathrm{O}_{2}$ concentrations on the catalytic activity of Au/TS-1: (c) propylene conversion ( $\square$ ) and PO selectivity $(\triangle)$, and $(\mathbf{d})$ PO rate $(\bigcirc)$ and $\mathrm{H}_{2}$ efficiency $(\diamond)$. Reproduced with permission from reference [62], copyright 2008, Elsevier B.V.

\section{Reaction Pathways}

In this last section, a brief review focusing on the mechanistic studies of the catalytic epoxidation of propylene with $\mathrm{H}_{2}$ and $\mathrm{O}_{2}$ by supported Au nanoparticles is given. Chowdhury et al. conducted in situ UV-vis and electron paramagnetic resonance (EPR) analyses to observe the adsorbed species of oxygen $\left(\mathrm{O}^{2-}\right)$ on the Au surfaces and the structure of the hydroperoxo species on the tetrahedral $\mathrm{Ti}^{4+}$ in $\mathrm{Au} / \mathrm{Ti}-\mathrm{SiO}_{2}$, which promote the epoxidation of propylene [17]. In this concept, the hydroperoxo species react with propylene to produce the PO, as shown in Figure 14 [65-67]. This result is consistent with those of previous studies $[15,68,69]$. 


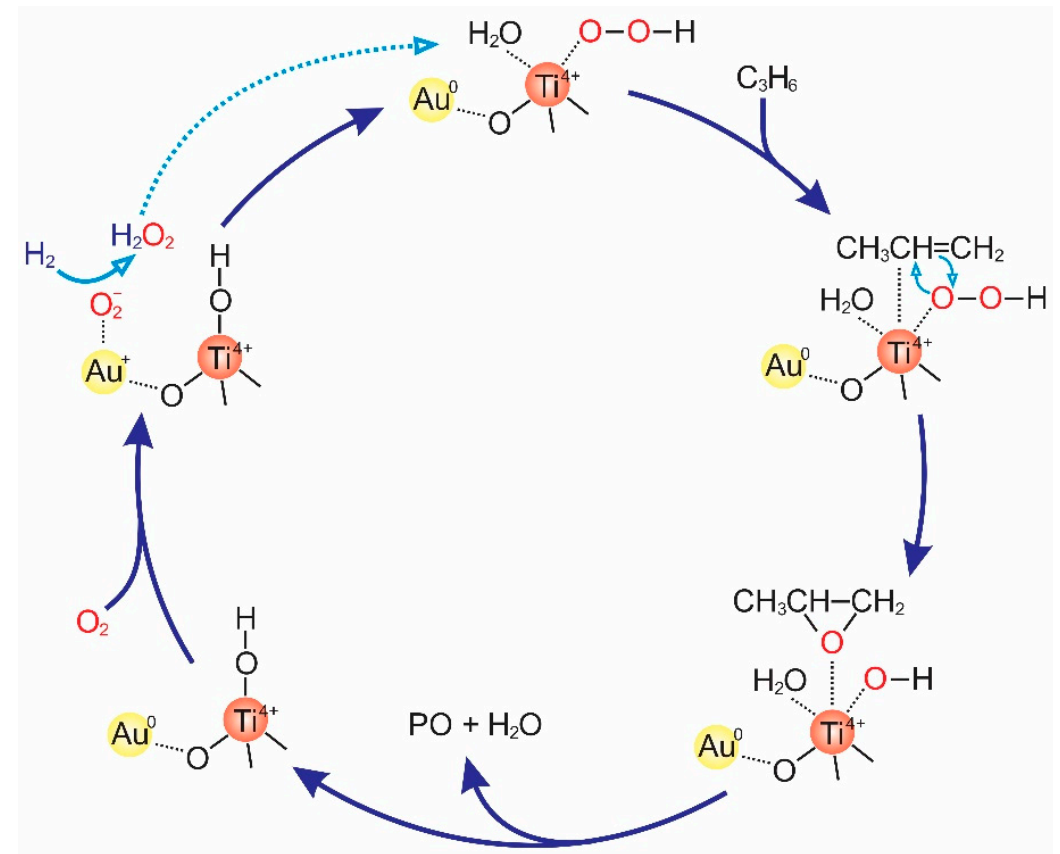

Figure 14. A possible mechanism to generate PO over Au-supported titanosilicates. Redrawn with permission from reference [67], copyright 2008, American Chemical Society.

Based on the products generated during the reaction, Zhan et al. proposed reaction pathways for the epoxidation of propylene using the $\mathrm{Au} / \mathrm{TS}-1$ catalyst, as illustrated in Figure 15 [41]. Clearly, acrolein (propenal), along with $\mathrm{PO}$ and $\mathrm{CO}_{2}$, were the primary products at the initial stage of the reaction. Acetone and acetaldehyde (ethanal) were formed as secondary products.

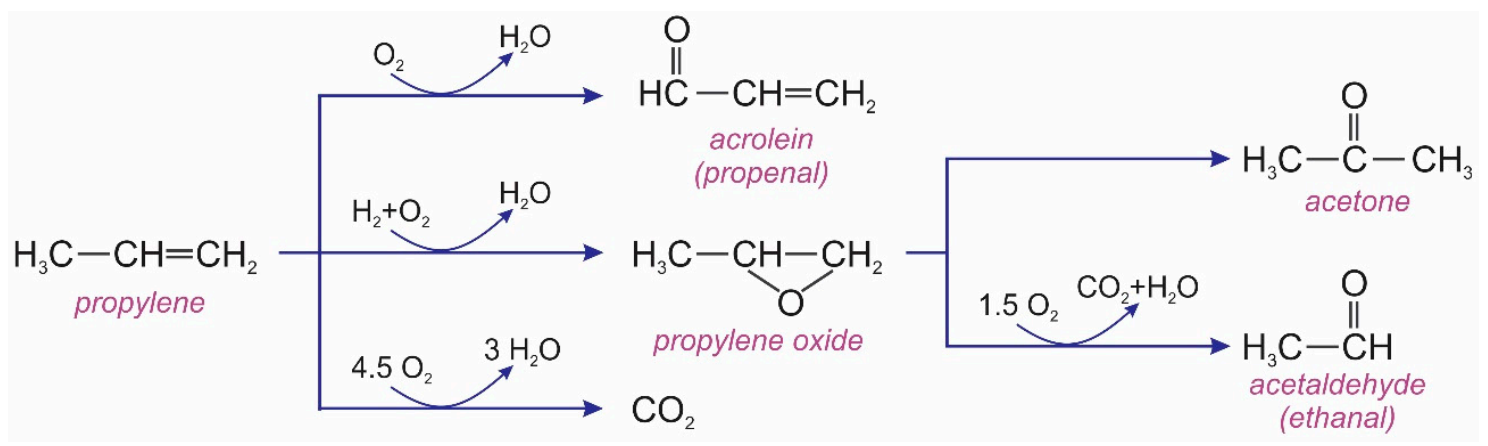

Figure 15. Possible reaction pathways for the epoxidation of propylene using the Au/TS-1 catalyst.

\section{Conclusions}

We have comprehensively reviewed and provided insights into the recent developments on $\mathrm{Au}$ nanoparticles for the catalytic epoxidation of propylene with $\mathrm{H}_{2}$ and $\mathrm{O}_{2}$. Over the last two decades, substantial progress has been made to improve the production of $\mathrm{PO}$, including the design of highly dispersed Au catalysts on various types of support material, optimization of the catalytic epoxidation conditions, and determination of the mechanisms and reaction pathways of epoxidation. In particular, the critical roles of catalyst synthesis and post-treatment methods, nature of material supports, and size distributions and loading amounts of Au nanoparticles have been emphasized.

Future studies are expected to continually focus on the design of new, practical, robust, and highly PO-selective supported Au nanoparticle catalyst systems for the epoxidation of propylene. To further enhance the catalytic performance, the following criteria should be directly addressed. Firstly, the effects of low and high dispersions of Au nanoparticles, hydrophobic supports, and the mechanisms of loss of stability and deactivation of catalytic activity should be determined at a fundamental level. 
Understanding their roles could provide guidelines for the design of novel active and stable catalysts. Secondly, novel catalytic systems should be designed, including the reactors, reaction conditions, and methods for the scaling-up of the processes that should be established. Thirdly, the most critical engineering issue that should be addressed are the safety requirements for $\mathrm{H}_{2}, \mathrm{O}_{2}$, and organic compound mixtures.

Author Contributions: V.-H.N., B.-S.N., S.Y.K. and Q.V.L. conceived the idea and supervised the project. All authors have read and agreed to the published version of the manuscript.

Funding: This research was funded by the Bio \& Medical Technology Development Program [grant number 2018M3A9H1023141]; the Creative Materials Discovery Program through the NRF funded by Ministry of Science and ICT [grant number 2017M3D1A1039379]; and the Basic Research Laboratory of the NRF funded by the Korean government [grant number 2018R1A4A1022647].

Conflicts of Interest: The authors declare no conflict of interest.

\section{References}

1. Nguyen, V.-H.; Nguyen, B.-S.; Vo, H.-T.; Nguyen, C.C.; Bae, S.-R.; Kim, S.Y.; Le, Q.V. Recent Advances in Selective Photo-Epoxidation of Propylene: A Review. Catalysts 2020, 10, 87. [CrossRef]

2. Baer, H.; Bergamo, M.; Forlin, A.; Pottenger, L.H.; Lindner, J. Propylene oxide. In Ullmann's Encyclopedia of Industrial Chemistry; MCB UP Ltd.: Bingley, UK, 2012.

3. Tsuji, J.; Yamamoto, J.; Ishino, M.; Oku, N. Development of new propylene oxide process. Sumitomo Kagaku 2006, 1, 4-10.

4. Russo, V.; Tesser, R.; Santacesaria, E.; Di Serio, M. Chemical and Technical Aspects of Propene Oxide Production via Hydrogen Peroxide (HPPO Process). Ind. Eng. Chem. Res. 2013, 52, 1168-1178. [CrossRef]

5. Nijhuis, T.A.; Makkee, M.; Moulijn, J.A.; Weckhuysen, B.M. The Production of Propene Oxide: Catalytic Processes and Recent Developments. Ind. Eng. Chem. Res. 2006, 45, 3447-3459. [CrossRef]

6. Farinas, E.T.; Alcalde, M.; Arnold, F. Alkene epoxidation catalyzed by cytochrome P450 BM-3 139-3. Tetrahedron 2004, 60, 525-528. [CrossRef]

7. Amano, F.; Tanaka, T. Modification of photocatalytic center for photo-epoxidation of propylene by rubidium ion addition to V2O5/SiO2. Catal. Commun. 2005, 6, 269-273. [CrossRef]

8. Nguyen, V.-H.; Lin, S.D.; Wu, J.C.-S. Synergetic photo-epoxidation of propylene over VTi/MCM-41 mesoporous photocatalysts. J. Catal. 2015, 331, 217-227. [CrossRef]

9. Nguyen, V.-H.; Lin, S.D.; Wu, J.C.-S.; Bai, H. Artificial sunlight and ultraviolet light induced photo-epoxidation of propylene over V-Ti/MCM-41 photocatalyst. Beilstein J. Nanotechnol. 2014, 5, 566-576. [CrossRef]

10. Nguyen, V.-H.; Chan, H.-Y.; Wu, J.C.S. Synthesis, characterization and photo-epoxidation performance of Au-loaded photocatalysts. J. Chem. Sci. 2013, 125, 859-867. [CrossRef]

11. Nguyen, V.-H.; Wu, J.C.S.; Bai, H. Temperature effect on the photo-epoxidation of propylene over V-Ti/MCM-41 photocatalyst. Catal. Commun. 2013, 33, 57-60. [CrossRef]

12. Nguyen, V.-H.; Chan, H.-Y.; Wu, J.C.S.; Bai, H. Direct gas-phase photocatalytic epoxidation of propylene with molecular oxygen by photocatalysts. Chem. Eng. J. 2012, 179, 285-294. [CrossRef]

13. Goodridge, F.; Harrison, S.; Plimley, R.E. The electrochemical production of propylene oxide. J. Electroanal. Chem. Interf. Electrochem. 1986, 214, 283-293. [CrossRef]

14. Hayashi, T.; Tanaka, K.; Haruta, M. Selective Vapor-Phase Epoxidation of Propylene over Au/TiO2Catalysts in the Presence of Oxygen and Hydrogen. J. Catal. 1998, 178, 566-575. [CrossRef]

15. Uphade, B.S.; Akita, T.; Nakamura, T.; Haruta, M. Vapor-Phase Epoxidation of Propene Using H2 and O2 over Au/Ti-MCM-48. J. Catal. 2002, 209, 331-340. [CrossRef]

16. Sinha, A.K.; Seelan, S.; Tsubota, S.; Haruta, M. Catalysis by Gold Nanoparticles: Epoxidation of Propene. Top. Catal. 2004, 29, 95-102. [CrossRef]

17. Chowdhury, B.; Bravo-Suárez, J.J.; Mimura, N.; Lu, J.; Bando, K.K.; Tsubota, S.; Haruta, M. In Situ UV-vis and EPR Study on the Formation of Hydroperoxide Species during Direct Gas Phase Propylene Epoxidation over Au/Ti-SiO2 Catalyst. J. Phys. Chem. B 2006, 110, 22995-22999. [CrossRef] [PubMed]

18. Masatake, H.; Tetsuhiko, K.; Hiroshi, S.; Nobumasa, Y. Novel Gold Catalysts for the Oxidation of Carbon Monoxide at a Temperature far Below $0{ }^{\circ} \mathrm{C}$. Chem. Lett. 1987, 16, 405-408. [CrossRef] 
19. Uphade, B.S.; Yamada, Y.; Akita, T.; Nakamura, T.; Haruta, M. Synthesis and characterization of Ti-MCM-41 and vapor-phase epoxidation of propylene using $\mathrm{H} 2$ and $\mathrm{O} 2$ over Au/Ti-MCM-41. Appl. Catal. A 2001, 215, 137-148. [CrossRef]

20. Feng, X.; Duan, X.; Qian, G.; Zhou, X.; Chen, D.; Yuan, W. Insights into size-dependent activity and active sites of Au nanoparticles supported on TS-1 for propene epoxidation with H2 and O2. J. Catal. 2014, 317, 99-104. [CrossRef]

21. Taylor, B.; Lauterbach, J.; Delgass, W.N. Gas-phase epoxidation of propylene over small gold ensembles on TS-1. Appl. Catal. A 2005, 291, 188-198. [CrossRef]

22. Huang, J.; Lima, E.; Akita, T.; Guzmán, A.; Qi, C.; Takei, T.; Haruta, M. Propene epoxidation with O2 and H2: Identification of the most active gold clusters. J. Catal. 2011, 278, 8-15. [CrossRef]

23. Yap, N.; Andres, R.P.; Delgass, W.N. Reactivity and stability of Au in and on TS-1 for epoxidation of propylene with $\mathrm{H} 2$ and O2. J. Catal. 2004, 226, 156-170. [CrossRef]

24. Shekhar, M.; Wang, J.; Lee, W.-S.; Williams, W.D.; Kim, S.M.; Stach, E.A.; Miller, J.T.; Delgass, W.N.; Ribeiro, F.H. Size and Support Effects for the Water-Gas Shift Catalysis over Gold Nanoparticles Supported on Model Al2O3 and TiO2. J. Am. Chem. Soc. 2012, 134, 4700-4708. [CrossRef] [PubMed]

25. Williams, W.D.; Shekhar, M.; Lee, W.-S.; Kispersky, V.; Delgass, W.N.; Ribeiro, F.H.; Kim, S.M.; Stach, E.A.; Miller, J.T.; Allard, L.F. Metallic Corner Atoms in Gold Clusters Supported on Rutile Are the Dominant Active Site during Water-Gas Shift Catalysis. J. Am. Chem. Soc. 2010, 132, 14018-14020. [CrossRef]

26. Janssens, T.V.W.; Clausen, B.S.; Hvolbæk, B.; Falsig, H.; Christensen, C.H.; Bligaard, T.; Nørskov, J.K. Insights into the reactivity of supported Au nanoparticles: Combining theory and experiments. Top. Catal. 2007, 44, 15-26. [CrossRef]

27. Chen, J.; Halin, S.J.A.; Pidko, E.A.; Verhoeven, M.W.G.M.; Ferrandez, D.M.P.; Hensen, E.J.M.; Schouten, J.C.; Nijhuis, T.A. Enhancement of Catalyst Performance in the Direct Propene Epoxidation: A Study into Gold-Titanium Synergy. ChemCatChem 2013, 5, 467-478. [CrossRef]

28. Kanungo, S.; Keshri, K.S.; Van Hoof, A.J.F.; D'Angelo, M.F.N.; Schouten, J.C.; Nijhuis, T.A.; Hensen, E.J.M.; Chowdhury, B. Silylation enhances the performance of $\mathrm{Au} / \mathrm{Ti}-\mathrm{SiO} 2$ catalysts in direct epoxidation of propene using $\mathrm{H} 2$ and O2. J. Catal. 2016, 344, 434-444. [CrossRef]

29. Lu, J.; Zhang, X.; Bravo-Suárez, J.J.; Bando, K.K.; Fujitani, T.; Oyama, S.T. Direct propylene epoxidation over barium-promoted Au/Ti-TUD catalysts with $\mathrm{H} 2$ and O2: Effect of Au particle size. J. Catal. 2007, 250, 350-359. [CrossRef]

30. Sacaliuc, E.; Beale, A.M.; Weckhuysen, B.M.; Nijhuis, T.A. Propene epoxidation over Au/Ti-SBA-15 catalysts. J. Catal. 2007, 248, 235-248. [CrossRef]

31. Liu, C.-H.; Guan, Y.; Hensen, E.J.M.; Lee, J.-F.; Yang, C.-M. Au/TiO2@SBA-15 nanocomposites as catalysts for direct propylene epoxidation with $\mathrm{O} 2$ and $\mathrm{H} 2$ mixtures. J. Catal. 2011, 282, 94-102. [CrossRef]

32. Sinha, A.K.; Seelan, S.; Akita, T.; Tsubota, S.; Haruta, M. Vapor phase propylene epoxidation over Au/Ti-MCM-41 catalysts prepared by different Ti incorporation modes. Appl. Catal. A 2003, 240, 243-252. [CrossRef]

33. Uphade, B.S.; Okumura, M.; Tsubota, S.; Haruta, M. Effect of physical mixing of CsCl with Au/Ti-MCM-41 on the gas-phase epoxidation of propene using $\mathrm{H} 2$ and $\mathrm{O} 2::$ Drastic depression of $\mathrm{H} 2$ consumption. Appl. Catal. A 2000, 190, 43-50. [CrossRef]

34. Jin, F.; Wu, Y.; Liu, S.; Lin, T.-H.; Lee, J.-F.; Cheng, S. Effect of Ti incorporated MWW supports on Au loading and catalytic performance for direct propylene epoxidation. Catal. Today 2016, 264, 98-108. [CrossRef]

35. Ren, Y.; Xu, L.; Zhang, L.; Wang, J.; Liu, Y.; He, M.; Wu, P. Selective epoxidation of propylene to propylene oxide with $\mathrm{H} 2$ and $\mathrm{O} 2$ over Au/Ti-MWW catalysts. Pure Appl. Chem. 2011, 84, 561-578. [CrossRef]

36. Haruta, M.; Uphade, B.S.; Tsubota, S.; Miyamoto, A. Selective oxidation of propylene over gold deposited on titanium-based oxides. Res. Chem. Intermed. 1998, 24, 329-336. [CrossRef]

37. Lee, W.-S.; Cem Akatay, M.; Stach, E.A.; Ribeiro, F.H.; Nicholas Delgass, W. Enhanced reaction rate for gas-phase epoxidation of propylene using $\mathrm{H} 2$ and $\mathrm{O} 2$ by Cs promotion of Au/TS-1. J. Catal. 2013, 308, 98-113. [CrossRef]

38. Lee, W.-S.; Akatay, M.C.; Stach, E.A.; Ribeiro, F.H.; Delgass, W.N. Gas-phase epoxidation of propylene in the presence of $\mathrm{H} 2$ and $\mathrm{O} 2$ over small gold ensembles in uncalcined TS-1. J. Catal. 2014, 313, 104-112. [CrossRef]

39. Huang, J.; Takei, T.; Akita, T.; Ohashi, H.; Haruta, M. Gold clusters supported on alkaline treated TS-1 for highly efficient propene epoxidation with $\mathrm{O} 2$ and H2. Appl. Catal. B 2010, 95, 430-438. [CrossRef] 
40. Ren, Y.-G.; Huang, J.; Lv, Q.; Xie, Y.; Lu, A.-H.; Haruta, M. Dual-component gas pretreatment for Au/TS-1: Enhanced propylene epoxidation with oxygen and hydrogen. Appl. Catal. A 2019, 584, 117172. [CrossRef]

41. Zhan, G.; Du, M.; Sun, D.; Huang, J.; Yang, X.; Ma, Y.; Ibrahim, A.-R.; Li, Q. Vapor-Phase Propylene Epoxidation with H2/O2 over Bioreduction Au/TS-1 Catalysts: Synthesis, Characterization, and Optimization. Ind. Eng. Chem. Res. 2011, 50, 9019-9026. [CrossRef]

42. Feng, X.; Duan, X.; Cheng, H.; Qian, G.; Chen, D.; Yuan, W.; Zhou, X. Au/TS-1 catalyst prepared by deposition-precipitation method for propene epoxidation with $\mathrm{H} 2 / \mathrm{O} 2$ : Insights into the effects of slurry aging time and Si/Ti molar ratio. J. Catal. 2015, 325, 128-135. [CrossRef]

43. Lu, J.; Zhang, X.; Bravo-Suárez, J.J.; Fujitani, T.; Oyama, S.T. Effect of composition and promoters in Au/TS-1 catalysts for direct propylene epoxidation using H2 and O2. Catal. Today 2009, 147, 186-195. [CrossRef]

44. Li, Z.; Wang, Y.; Zhang, J.; Wang, D.; Ma, W. Better performance for gas-phase epoxidation of propylene using $\mathrm{H} 2$ and $\mathrm{O} 2$ at lower temperature over Au/TS-1 catalyst. Catal. Commun. 2017, 90, 87-90. [CrossRef]

45. Xu, L.; Ren, Y.; Wu, H.; Liu, Y.; Wang, Z.; Zhang, Y.; Xu, J.; Peng, H.; Wu, P. Core/shell-structured TS-1@mesoporous silica-supported Au nanoparticles for selective epoxidation of propylene with $\mathrm{H} 2$ and $\mathrm{O} 2$. J. Mater. Chem. 2011, 21, 10852-10858. [CrossRef]

46. Li, N.; Chen, Y.; Shen, Q.; Yang, B.; Liu, M.; Wei, L.; Tian, W.; Zhou, J. TS-1 supported highly dispersed sub-5 $\mathrm{nm}$ gold nanoparticles toward direct propylene epoxidation using $\mathrm{H} 2$ and O2. J. Solid State Chem. 2018, 261, 92-102. [CrossRef]

47. Zhang, Z.; Zhao, X.; Wang, G.; Xu, J.; Lu, M.; Tang, Y.; Fu, W.; Duan, X.; Qian, G.; Chen, D.; et al. Uncalcined TS-2 immobilized Au nanoparticles as a bifunctional catalyst to boost direct propylene epoxidation with $\mathrm{H} 2$ and O2. AIChE J. 2020, 66, e16815. [CrossRef]

48. Nijhuis, T.A.; Gardner, T.Q.; Weckhuysen, B.M. Modeling of kinetics and deactivation in the direct epoxidation of propene over gold-titania catalysts. J. Catal. 2005, 236, 153-163. [CrossRef]

49. Min, B.K.; Wallace, W.T.; Goodman, D.W. Synthesis of a Sinter-Resistant, Mixed-Oxide Support for Au Nanoclusters. J. Phys. Chem. B 2004, 108, 14609-14615. [CrossRef]

50. Du, M.; Huang, J.; Sun, D.; Li, Q. Propylene epoxidation over biogenic Au/TS-1 catalysts by Cinnamomum camphora extract in the presence of $\mathrm{H} 2$ and O2. Appl. Surf. Sci. 2016, 366, 292-298. [CrossRef]

51. Feng, X.; Liu, Y.; Li, Y.; Yang, C.; Zhang, Z.; Duan, X.; Zhou, X.; Chen, D. Au/TS-1 catalyst for propene epoxidation with $\mathrm{H} 2 / \mathrm{O} 2$ : A novel strategy to enhance stability by tuning charging sequence. AIChE J. 2016, 62, 3963-3972. [CrossRef]

52. Song, Z.; Feng, X.; Sheng, N.; Lin, D.; Li, Y.; Liu, Y.; Chen, X.; Chen, D.; Zhou, X.; Yang, C. Cost-efficient core-shell TS-1/silicalite-1 supported Au catalysts: Towards enhanced stability for propene epoxidation with H2 and O2. Chem. Eng. J. 2019, 377, 119927. [CrossRef]

53. Sheng, N.; Liu, Z.; Song, Z.; Lin, D.; Feng, X.; Liu, Y.; Chen, X.; Chen, D.; Zhou, X.; Yang, C. Enhanced stability for propene epoxidation with $\mathrm{H} 2$ and $\mathrm{O} 2$ over wormhole-like hierarchical TS-1 supported Au nanocatalyst. Chem. Eng. J. 2019, 377, 119954. [CrossRef]

54. Feng, X.; Duan, X.; Qian, G.; Zhou, X.; Chen, D.; Yuan, W. Au nanoparticles deposited on the external surfaces of TS-1: Enhanced stability and activity for direct propylene epoxidation with $\mathrm{H} 2$ and O2. Appl. Catal. B 2014, 150-151, 396-401. [CrossRef]

55. Haruta, M. Catalysis of Gold Nanoparticles Deposited on Metal Oxides. Cattech 2002, 6, 102-115. [CrossRef]

56. Haruta, M.; Daté, M. Advances in the catalysis of Au nanoparticles. Appl. Catal. A 2001, 222, $427-437$. [CrossRef]

57. Du, M.; Zhan, G.; Yang, X.; Wang, H.; Lin, W.; Zhou, Y.; Zhu, J.; Lin, L.; Huang, J.; Sun, D.; et al. Ionic liquid-enhanced immobilization of biosynthesized Au nanoparticles on TS-1 toward efficient catalysts for propylene epoxidation. J. Catal. 2011, 283, 192-201. [CrossRef]

58. Cumaranatunge, L.; Delgass, W.N. Enhancement of Au capture efficiency and activity of Au/TS-1 catalysts for propylene epoxidation. J. Catal. 2005, 232, 38-42. [CrossRef]

59. Chowdhury, B.; Bravo-Suárez, J.J.; Daté, M.; Tsubota, S.; Haruta, M. Trimethylamine as a Gas-Phase Promoter: Highly Efficient Epoxidation of Propylene over Supported Gold Catalysts. Angew. Chem. Int. Ed. 2006, 45, 412-415. [CrossRef] [PubMed]

60. Shin, S.B.; Lee, D.-W.; Chadwick, D. The effects of impregnation of precious metals on the catalytic activity of titanium silicate (TS-1) in epoxidation of propene using hydrogen peroxide. J. Mol. Catal. A 2016, 423, 478-488. [CrossRef] 
61. Lu, M.; Tang, Y.; Chen, W.; Ye, G.; Qian, G.; Duan, X.; Yuan, W.; Zhou, X. Explosion limits estimation and process optimization of direct propylene epoxidation with $\mathrm{H} 2$ and O2. Chin. J. Chem. Eng. 2019, 27, 2968-2978. [CrossRef]

62. Oyama, S.T.; Zhang, X.; Lu, J.; Gu, Y.; Fujitani, T. Epoxidation of propylene with $\mathrm{H} 2$ and $\mathrm{O} 2$ in the explosive regime in a packed-bed catalytic membrane reactor. J. Catal. 2008, 257, 1-4. [CrossRef]

63. Chen, L.Y.; Chuah, G.K.; Jaenicke, S. Propylene epoxidation with hydrogen peroxide catalyzed by molecular sieves containing framework titanium. J. Mol. Catal. A 1998, 132, 281-292. [CrossRef]

64. Schröder, V.; Emonts, B.; Janßen, H.; Schulze, H.-P. Explosion Limits of Hydrogen/Oxygen Mixtures at Initial Pressures up to 200 bar. Chem. Eng. Technol. 2004, 27, 847-851. [CrossRef]

65. Wells, D.H.; Delgass, W.N.; Thomson, K.T. Evidence of Defect-Promoted Reactivity for Epoxidation of Propylene in Titanosilicate (TS-1) Catalysts: A DFT Study. J. Am. Chem. Soc. 2004, 126, 2956-2962. [CrossRef] [PubMed]

66. Lu, J.; Zhang, X.; Bravo-Suárez, J.J.; Tsubota, S.; Gaudet, J.; Oyama, S.T. Kinetics of propylene epoxidation using $\mathrm{H} 2$ and $\mathrm{O} 2$ over a gold/mesoporous titanosilicate catalyst. Catal. Today 2007, 123, 189-197. [CrossRef]

67. Bravo-Suárez, J.J.; Bando, K.K.; Lu, J.; Haruta, M.; Fujitani, T.; Oyama, T. Transient Technique for Identification of True Reaction Intermediates: Hydroperoxide Species in Propylene Epoxidation on Gold/Titanosilicate Catalysts by X-ray Absorption Fine Structure Spectroscopy. J. Phys. Chem. C 2008, 112, 1115-1123. [CrossRef]

68. Joshi, A.M.; Delgass, W.N.; Thomson, K.T. Mechanistic Implications of Aun/Ti-Lattice Proximity for Propylene Epoxidation. J. Phys. Chem. C 2007, 111, 7841-7844. [CrossRef]

69. Wells, D.H.; Delgass, W.N.; Thomson, K.T. Formation of hydrogen peroxide from H2 and O2 over a neutral gold trimer: A DFT study. J. Catal. 2004, 225, 69-77. [CrossRef]

(C) 2020 by the authors. Licensee MDPI, Basel, Switzerland. This article is an open access article distributed under the terms and conditions of the Creative Commons Attribution (CC BY) license (http://creativecommons.org/licenses/by/4.0/). 